\title{
The protein-protein interaction network of first episode psychosis and schizophrenia reveals possible trigger factors and new drug targets among intracellular signal transduction pathways and neurotoxicity processes.
}

Michael Maes, M.D., Ph.D. a,b,c, Kitiporn Plaimas, Dr.rer.nat. d, Apichat Suratanee, Dr.rer.nat. e , Cristiano Noto, M.D. f,g, Buranee Kanchanatawan, M.D. ${ }^{\text {a }}$

${ }^{a}$ Department of Psychiatry, Faculty of Medicine, Chulalongkorn University, Bangkok, Thailand

${ }^{\mathrm{b}}$ Department of Psychiatry, Medical University of Plovdiv, Plovdiv, Bulgaria

${ }^{\mathrm{c}}$ IMPACT Strategic Research Center, Deakin University, Geelong, Australia

${ }^{\mathrm{d}}$ Advanced Virtual and Intelligent Computing (AVIC) Center, Department of Mathematics and Computer Science, Faculty of Science, Chulalongkorn University, Bangkok, 10330, Thailand

e Department of Mathematics, Faculty of Applied Science, King Mongkut's University of Technology North Bangkok, Bangkok 10800, Thailand

${ }^{\mathrm{f}}$ GAPi (Early Psychosis Group), Universidade Federal de São Paulo (UNIFESP), São Paulo, Brazil.

g Schizophrenia Program (PROESQ), Department of Psychiatry, Universidade Federal de São Paulo (UNIFESP), São Paulo, Brazil

Corresponding author:

Prof. Dr. Michael Maes, M.D., Ph.D.

IMPACT Strategic Research Center

Barwon Health

Deakin University

Geelong, Vic

Australia

dr.michaelmaes@hotmail.com

https://scholar.google.co.th/citations?user=1wzMZ7UAAAAJ\&hl=th\&oi=ao

Michael Maes: dr.michaelmaes@,hotmail.com

Kitiporn Plaimas: kplaimas@gmail.com

Apichat Suratanee: apichat.s@sci.kmutnb.ac.th

Cristiano Noto: csnoto@gmail.com

Buranee Kanchanatawan: drburanee@gmail.com 


\begin{abstract}
There is evidence that schizophrenia is characterized by activation of the immune-inflammatory response (IRS) and compensatory immune-regulatory (CIRS) systems and lowered neuroprotection. Studies performed on antipsychotic-naïve first episode psychosis (AF-FEP) and schizophrenia (FES) patients are important as they may disclose the pathogenesis of the disease. However, the interactome of FEP/FES is not well delineated. The aim of the current study was to delineate the characteristics of the protein-protein interaction (PPI) network of AN-FEP and its transition to FES and the biological functions, pathways, and molecular patterns, which are overrepresented in FEP/FES. PPI network analysis shows that FEP and FEP/FES are strongly associated with a response to a bacterium, TNF, NFKB, RELA, SP1, JAK-STAT, death receptor and TLR4 signaling, and tyrosine phosphorylation of STAT proteins. Specific molecular complexes of the peripheral immune response are associated with microglial activation, neuroinflammation and gliogenesis. FEP/FES is accompanied by lowered protection against inflammation in part attributable to dysfunctional miRNA maturation, deficits in neurotrophin/Trk, RTK and Wnt/catenin signaling and adherens junction organization. Lowered neuroprotection due to reduced neurotrophin/Trk and Wnt/catenin signaling, and DISC1 expression and multiple interactions between lowered BDNF, CDH1, CTNNB, and DISC1 expression, increase the vulnerability to the neurotoxic effects of immune products including cytokines and complement factors. All pathways or molecular patterns enriched in the interactome of FEP/FES are directly or indirectly affected by LPS. In summary: FEP appears to be triggered by a biotic stimulus (e.g. Gram-negative bacteria) which may induce neuro-immune toxicity cascades especially when antiinflammatory and neurotrophic protections are deficient.
\end{abstract}

Key words: schizophrenia, neuro-immune, inflammation, physiological stress, bacterial translocation, psychiatry, LPS 
Introduction

In 1995, Smith and Maes [1] launched the monocyte-T lymphocyte theory of schizophrenia, which incorporated neurodevelopmental factors and activation of immune pathways into a first comprehensive theory of schizophrenia. This theory considered that a neurodevelopmental pathology due to prenatal bacterial or viral infections increases the vulnerability to a later immune-inflammatory hit whereby products of activated macrophages and T lymphocytes, including cytokines and tryptophan catabolites (TRYCAT), result in neurotoxic effects on brain cells [1]. The presence of an inflammatory process in schizophrenia was first reported in 1997 when Maes et al. [2] showed increased plasma levels of complement component 3 (C3C) and $\mathrm{C} 4$, positive acute phase proteins, including haptoglobin (Hp) [2], and interleukin (IL)-6 [3], one of the cytokines which initiates the acute phase response in schizophrenia. These pioneering findings were replicated in later studies [4] which additionally showed immuneinflammatory processes in the CNS and associations between schizophrenia and immune genes including single nucleotide polymorphisms in tumor necrosis factor (TNF)- $\alpha[5,6]$.

There is now evidence that schizophrenia phenotypes are accompanied by activation of the immune-inflammatory response system (IRS), including first episode psychosis (FEP), first episode schizophrenia (FES), multiple episode schizophrenia (MES), MES with worsening, the acute phase of schizophrenia, chronic schizophrenia, treatment resistant schizophrenia, deficit schizophrenia, and schizophrenia with comorbid mood symptoms and chronic fatigue-like symptoms [4,7]. In these different phenotypes, IRS activation with increased M1 macrophage, T helper (Th)-1 and Th-17 activation, is accompanied by activation of the compensatory immuneregulatory system (CIRS) as indicated by increased levels of immune-regulatory pathways including Th-2 and T regulatory cytokines, such as IL-10, IL-4 and IL-13, acute phase reactants, such as Hp, and TRYCAT levels [4,7]. As a consequence, the schizophrenia phenotypes present with a new homeostatic setpoint between both upregulated IRS and CIRS pathways, although there are indicants that the CIRS is dysfunctional in some phenotypes $[4,7,8]$.

Studies on antipsychotic-naïve (AN)-FEP and FES patients are extremely important as the results disclose the pathogenesis of the disease and because the results are not affected by the effects of multiple episodes [8]. Moreover, the examination of AN-FEP may disclose causal pathways or molecular processes which are unaffected by the use of antipsychotics. AN-FEP is not only characterized by a cytokine storm with robust M1, Th-1, Th-17, Th-2 and Treg activation, but also by a greater IRS as compared with CIRS response [8]. Moreover, lowered CIRS protection due to relatively lower levels of the immune-regulatory soluble receptors (e.g. IL-2 receptor tumor necrosis factor (TNF) receptors) predicts a worse clinical outcome [8]. Furthermore, AN-FEP is accompanied by a) lowered expression of BDNF, DISC1 and DROSHA which exert neurotrophic, neuroprotective, and neurogenic functions and modulate microRNA (miRNA) biogenesis [9,10], and b) lowered activity of paraoxonase (PON)-1, an enzyme with anti-inflammatory, anti-oxidant, and anti-microbial properties [11]. FES which is the timely consequence of FEP is characterized by a) activated IRS/CIRS with increased levels of CCL11 (or eotaxin a neurotoxic Th-2-associated cytokine), TRYCATs, oxidative stress indicants, and IL-10; b) increased IgA C1q circulating immune complexes (CICs); c) disorders in the expression of $\beta$-catenin, E-cadherin, plasmalemma vesicle associated protein (PLVAP), indicating dysfunctions in cell-cell junction, and adherens and vascular junctions; d) increased $\operatorname{IgA} / \operatorname{IgM}$ responses to Gram-negative bacteria, including Klebsiella pneumoniae [7]; and e) lowered BDNF [12]. In FEP/FES, increased neurotoxicity due to $\mathrm{M} 1$, Th-1, and Th-2 activation contributes to a general cognitive decline (G-CoDe), which reflects abnormalities in brain connectome circuits [13]. 
However, many issues have remained elusive, as for example the identification of: a) the interactome and possible sub-networks in FEP and FES; b) the most influential core genes in the interactome, either hubs (disease causing genes) or bottlenecks (controlling the network); c) the biological functions, pathways, molecular patterns and cellular components that characterize FEP/FES; d) the possible trigger factors of the FEP/FES interactome; and e) the possible associations with other medical illness. Hence, the aim of the current study was to delineate the characteristics of the protein-protein interaction (PPI) network of AN-FEP and its transition to FES and the most significant paths, molecular patterns, cellular components, and diseases enriched in the PPI networks.

Methods

Selection of seed proteins

This study is a secondary data analysis on existing data using open, deidentified and noncoded data sets and, therefore, this is non-human subjects research which is not subject to IRB approval. In our previous case-control studies conducted in Brazil and Thai patients with AN-FEP and FES, we have identified differently expressed genes as compared with normal controls $[7,9,10,14,15]$. The patients were of both sexes and aged 18-65 years old. The socio-demographic and clinical data are displayed in $[7,9,10,14,15]$. In this study we examined PPI networks of two related phenotypes namely AN-FEP and the FEP/FES spectrum, which combines AN-FEP and FES data. As such, this study provides information of the onset of schizophrenia (FEP) and the first episode, which is the direct sequel of FEP. Overall 24 proteins were selected in FEP/FES, namely IL4; IL5; IL6; IL10; IL12A; IL13; IFNG (interferon- $\gamma$ ); TNF (tumor necrosis factor- $\alpha$ ); CSF2 (Granulocyte-macrophage colony-stimulating factor); CCL3 (C-C motif chemokine 3); CCL11 (C-C motif chemokine 11 or eotaxin); IL1RN (IL-1 receptor antagonist); C1QA (Complement C1q); PON1 (paraoxonase1); CDH1 (cadherin-1); CTNNB1 (Catenin beta-1); PLVAP (Plasmalemma vesicle-associated protein ); BDNF (brain-derived nuclear factor); COMT (Catechol O-methyltransferase); DROSHA (Ribonuclease III double-stranded (ds) RNA-specific endoribonuclease); DISC1 (Disrupted in schizophrenia 1 protein); NDEL1 (Nuclear distribution protein nudE-like 1) and MBP (myelin basic protein). The downregulated proteins were: COMT, DISC1, DROSHA, CDH1, CTNNB1, PLVAP, BDNF, and PON1. All other genes were upregulated. There were fifteen FEP-associated seed genes, namely IL5, IL6, IL10, IL12A, IL13, IFNG, TNF, CSF2, NDEL1, MBP, PON1, BDNF, COMT, DROSHA, and DISC1 [7,9,10114,15].

\section{PPI network construction.}

Construction of the PPI network with network expansion was conducted using STRING version 11.0 (https://string-db.org). The STRING database was employed to assess the PPIs (minimum required interaction score was 0.400 ) and to construct zero-order (seed proteins only) and first-order (50 interactions in the first shell, none in the second shell) PPI networks among the genes (set organism is homo sapiens). We examined the network characteristics (number of nodes and edges, average number of neighbors, network diameter and radius, clustering coefficient, and network density, heterogeneity and centralization) of the zero and first-order networks as well as further expanded networks using STRING and Cytoscape (https://cytoscape.org) plugins including NetworkAnalyzer (Cytoscape App Store - NetworkAnalyzer). Hub nodes were authenticated as the top 5 nodes with the highest degree, and top non-hub bottlenecks as nodes with the highest betweenness centrality. Together they shape the backbone of the network. 
Network clustering was carried out to cluster highly interconnected genes in order to identify protein communalities with similar attributes and functions. In the present study we employed STRING to perform Markov Clustering (MCL), which robustly identifies annotated complexes, and Cytoscape plugins, namely ClusterMaker. Molecular Complex Detection (MCODE) was performed using Metascape to detect smaller components of densely connected nodes which represent molecular complexes [17].

\section{Enrichment analysis.}

The list of seed and first-order genes (divided into communities by cluster analysis and upand downregulated genes) were extended with known protein interactions from STRING, IntAct (https://www.ebi.ac.uk/intact/), GOnet (https://tools.dice-database.org/Gonet/), Metascape (http://metascape.org), inBio Discover (https://inbio-discover.com/), Enrichr (https://maayanlab.cloud/Enrichr/) or the R package ClusterProfiler 4.0 [16] and examined for their pathway, function or disease enrichment scores. In this study we use the false discovery rate (FDR) corrected p-values. We searched the networks against GO biological processes (assemblies of molecular functions in pathways), GO molecular functions (protein activities at the molecular level), GO cellular component (location of the proteins) (www.geneontology.org), Kyoto Encyclopedia of Genes and Genomes (KEGG) pathways (https://genome.jp/kegg/), REACTOME (the European Bio- informatics Institute pathway database) (https://reactome.org), Translational Regulatory Relationships (TTRUST) (www.grnpedia.org), and DOID human disease phenotypes (Disease Ontology - Institute for Genome Sciences @, University of Maryland (diseaseontology.org). Moreover, Metascape was used to delineate and visualize the GO biological pathways and molecular processes, and PANTHER (PANTHER - Gene List Analysis (pantherdb.org)), REACTOME, KEGG, and Wiki (WikiPathways - WikiPathways) pathways, which are over-represented in the gene sets. Metascape automatically clusters hierarchically the significant terms into a tree based on Kappa-statistical similarities among their gene memberships. This is useful because GO terms heavily overlap and, therefore, output GO terms show a large degree of redundancy. The top-10 performing terms obtained with Enrichr are displayed as bar graphs produced with Appyters.

\section{Annotation analysis and annotation visualization.}

Annotation analysis was employed to examine GO terms annotating the genes assembled into functional sets. GOnet analysis was employed to construct interactive graphs which at the same time contain genes and GO terms. Furthermore, we made custom GO term annotation lists consisting of the most representative GO terms (by preference the significant children). inBio Discover was used to show the network with the top-4 selected DOID annotations. R package ClusterProfiler was employed to make dot plots of annotated GO term leaves with size of the dots indicating gene number and color of the dots the $\mathrm{p}$-values.

Results

The PPI network topography of FEP and FES/FEP.

All genes were used to construct an undirected network representing the protein interactions in FEP/FES. The zero-order network consisted of 23 nodes, the number of edges $(n=88)$ exceeded the expected number of edges $(n=24)$ with p-enrichment value of $1.0 \mathrm{e}-16$, and average node degree $=7.65$ and average local clustering coefficient $=0.709$. There were 3 singletons, namely PLVAP, DROSHA, and C1QA. Figure 1 displays the first order protein 
network which showed one singleton (PLVAP) and 92 nodes; the number of edges ( $n=1063$ ) exceeded the expected number of edges $(\mathrm{n}=273)$ with $\mathrm{p}$-enrichment value of $1.0 \mathrm{e}-16$, average node degree $=23.1$, average local clustering coefficient $=0.678$, average number of neighbors $=23.109$, network diameter $=4$ and radius $=2$, characteristic path length $=1.919$, network density $=0.254$ and heterogeneity $=0.586$.

Hub and betweenness analysis showed that IL6 (degree=62), TNF (58), IL10 (46), IL4 (42) and CSF2 (39) were the top 5 hubs, while CTNNB1 (betweenness centrality $=0.0449$ ), BDNF $(0.0285)$ and $\mathrm{CDH} 1(0.014)$ were the top 3 non-hub bottlenecks. Top rank hubs and bottlenecks (computed as $\mathrm{z}$ degree $+\mathrm{z}$ betweenness) computed for the selected 23 seed proteins in a further enlarged network showed that the most influential proteins were in descending order of importance: CTNNB1, IL6, TNF, CDH1, IL4, IL10, and BDNF.

Figure 1 shows the results of MCL cluster analysis with an inflation parameter $=2.5$. Two protein communalities were detected: 1) a first immune cluster was centered around CCL11, CCL3, CSF2, IFNG, IL10, IL12A, IL13, IL1R1, IL4, IL5, IL6, MBP, PON1, TNF and BDNF; and 2) a second cell-cell junction-associated cluster was centered around CDH1 and CTNNB1. In the first-order network, there were two switches connecting these clusters. The first bridge was $\mathrm{CDH} 1$, which belongs to cluster 2 and is connected with CTNNB1 and with 5 seed genes in cluster 1 (CSF2, IL4, TNF, IL10, and IL6). In the first-order network, CHD1 shows 11 connections with cluster 1 seed genes and 16 with cluster 2 seed genes. The second switch was BDNF, which belongs to cluster 1 and shows interconnections with 5 cluster 1 genes, namely IL6 (0.811), TNF (0.805), IL4 (0.695), IL10 (0.613), and IFNG (0.419) and with one cluster 2 gene, namely CTNBB1 (0.932). In the first-order network, BDNF shows 16 connections (at $>0.40$ ) with cluster 1 genes and 7 with cluster 2 genes. More specifically, BDNF shows interconnections at $>0.900$ with 4 cluster 1 genes, namely STAT3 (0.967), TRAF6 (0.926), NTF4 (0.993), and NGFR (0.996), and 3 cluster 2 genes, namely NTRK2 (0.998), CTNNA1 (0.910), and CTNND1 (0.907). Moreover, BDNF showed interactions with COMT (0.733) and DISC1 (0.640) which do not belong to either cluster 1 or 2 . We observed that AKT1, which belongs to cluster 1 in the firstorder network, might be another switch as it was interconnected with 11 cluster 1 seed proteins and with CTNNB1 and CDH1.

The seed proteins were used to construct a PPI network representing the protein interactions in FEP only. The first-order network (first shell) shows 65 nodes, the number of edges $(\mathrm{n}=811)$ exceeded the expected number of edges $(\mathrm{n}=193)$ with $\mathrm{p}$-enrichment value of $1.0 \mathrm{e}-16$, with average node degree $=25$, average local clustering coefficient $=0.75$, average number of neighbors $=24.954$, network diameter $=4$ and radius $=2$, characteristic path length $=1.780$, network density $=0.390$ and heterogeneity $=0.549$. The top- 5 hubs are in descending order of importance IL6 (87), TNF (85), IL10 (71), IL4 (71), and IFNG (68). BDNF was the most important bottleneck (0.0563), followed by IL6 (0.0473) and TNF (0.046). 


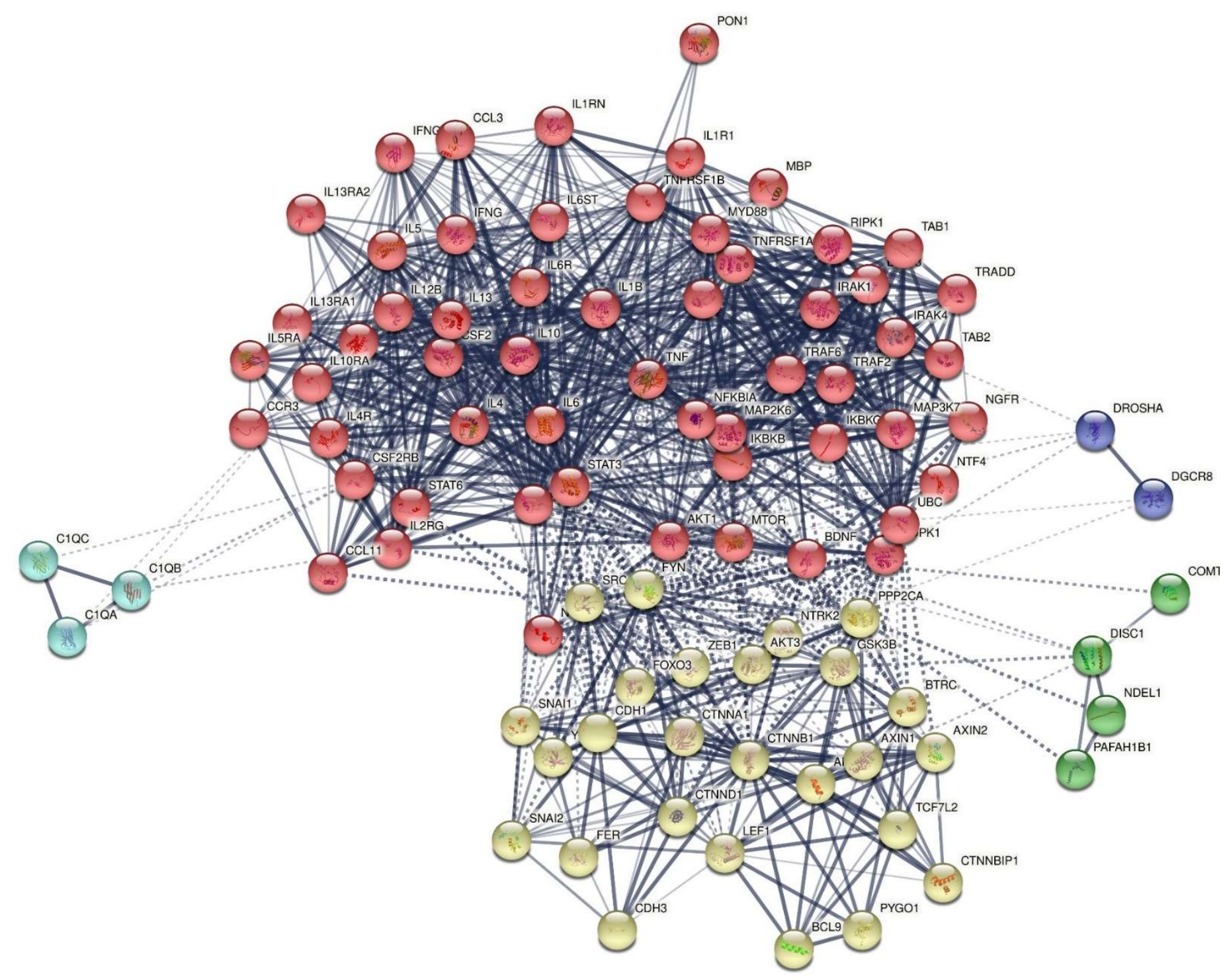

Figure 1. First order protein network showing 92 nodes and 1063 edges. MCL cluster analysis detected two clusters: 1) a first immune cluster (red color) was centered around BDNF, CCL11, CCL3, CSF2, IFNG, IL10, IL12A, IL13, IL1R1, IL4, IL5, IL6, MBP, PON1, and TNF, and 2) a second adhesion-associated cluster (yellow nodes) was centered around CDH1 and CTNNB1.

\section{Enrichment analysis in FEP.}

Figure 2 (upregulated genes) and Figure 3 (downregulated genes) show heatmaps (bar graphs) with the top-20 biological function GO enriched terms in FEP (shown are accumulative hypergeometric p-values). Figure 2 shows that the most important GO terms over-represented in the upregulated genes were: inflammatory response and cytokine production, and response to LPS and receptor signaling pathway via JAK-STAT. Figure 3 shows that the most important GO terms over-represented in the downregulated genes were: neurotrophin signaling pathway, production of miRNA involved in gene silencing, and neuron projection morphogenesis. 


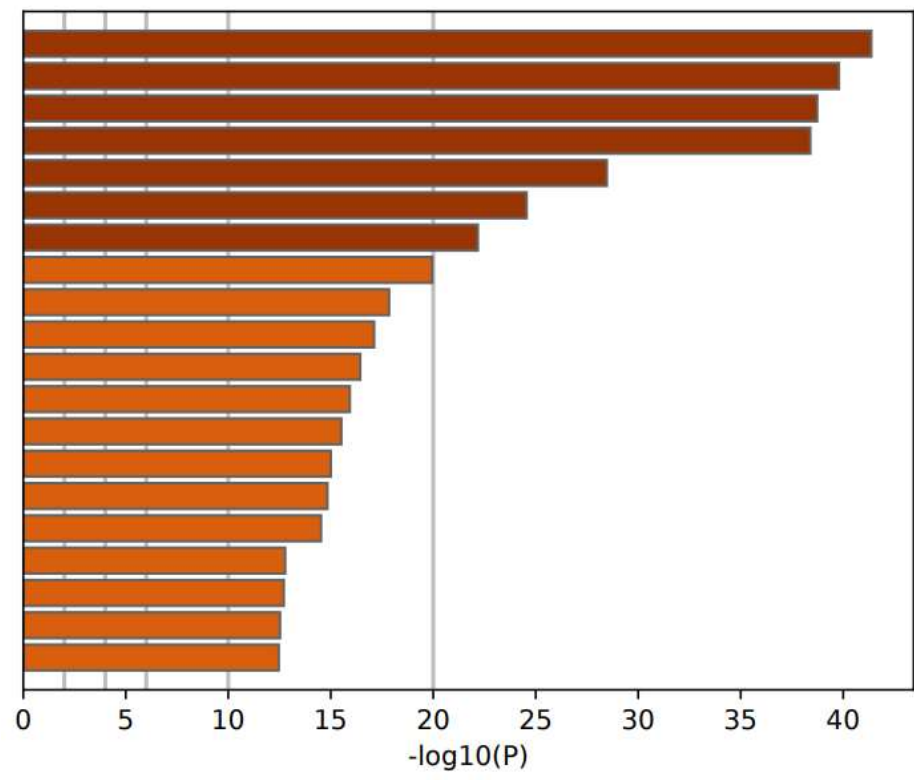

GO:0006954: inflammatory response GO:0032496: response to lipopolysaccharide GO:0001819: positive regulation of cytokine production GO:0007259: receptor signaling pathway via JAK-STAT GO:0071356: cellular response to tumor necrosis factor GO:0051090: regulation of DNA-binding transcription factor activity GO:0097191: extrinsic apoptotic signaling pathway GO:0009615: response to virus GO:0046425: regulation of receptor signaling pathway via JAK-STAT GO:0048660: regulation of smooth muscle cell proliferation GO:0071347: cellular response to interleukin-1 GO:0045637: regulation of myeloid cell differentiation GO:0071354: cellular response to interleukin-6 GO:1901214: regulation of neuron death GO:0002676: regulation of chronic inflammatory response GO:0038061: NIK/NF-kappaB signaling GO:0002274: myeloid leukocyte activation GO:0030335: positive regulation of cell migration GO:0031663: lipopolysaccharide-mediated signaling pathway GO:0032663: regulation of interleukin-2 production

Figure 2. Heatmap of enriched GO terms showing the top-20 biological functions overexpressed in the upregulated proteins of patients with first episode psychosis (accumulative hypergeometric p-values).

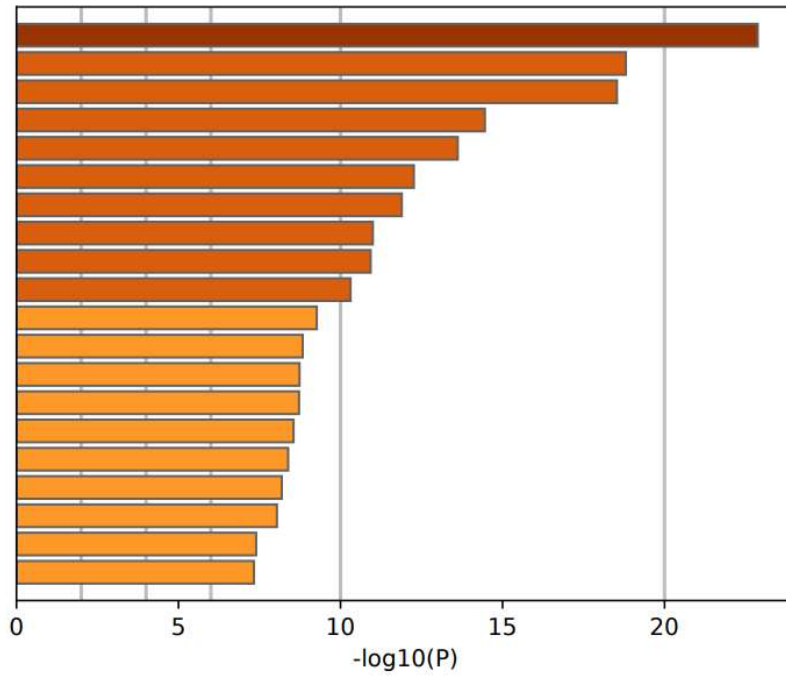

GO:0038179: neurotrophin signaling pathway

GO:0035196: production of miRNAs involved in gene silencing by miRNA GO:0048812: neuron projection morphogenesis

GO:1901615: organic hydroxy compound metabolic process

GO:0033674: positive regulation of kinase activity

GO:0120035: regulation of plasma membrane bounded cell projection organization GO:0010942: positive regulation of cell death

GO:0071417: cellular response to organonitrogen compound

GO:0007265: Ras protein signal transduction

GO:0097190: apoptotic signaling pathway

GO:2000251: positive regulation of actin cytoskeleton reorganization GO:0048511: rhythmic process

GO:0006584: catecholamine metabolic process

GO:0044089: positive regulation of cellular component biogenesis GO:0048514: blood vessel morphogenesis

GO:1903827: regulation of cellular protein localization

GO:0060148: positive regulation of posttranscriptional gene silencing

GO:0061061: muscle structure development

GO:0048013: ephrin receptor signaling pathway

GO:0070371: ERK1 and ERK2 cascade

Figure 3. Heatmap of enriched GO terms showing the top-20 biological functions overexpressed in the downregulated proteins of patients with first episode psychosis (accumulative hypergeometric p-values).

Table 1 shows the biological interpretation of the MCODE analysis performed using multiple databases (GO biological and molecular, KEGG, WikiPaths, PANTHER, and REACTOME gene sets) in FEP. MCODE performed on the upregulated genes in FEP detected one cluster which represented a response to LPS, response to molecule of bacterial origin, and inflammatory response. A second MCODE analysis conducted on the upregulated genes revealed 
two molecular complexes, namely signaling by interleukins and a second which is shown in Table 1 representing TNFR1-induced NFKB signaling pathway, death receptor signaling, and TNF signaling. MCODE performed on the downregulated genes in FEP detected two small complexes which represented: 1) neurotrophin / tropomyosin related kinase B (TrkB) signaling pathway and cellular component morphogenesis; and 2) RNA interference, production of miRNAs involved in gene silencing by miRNA, and production of small RNA involved in gene silencing by RNA. The search for regulatory relationship using TTRUST (in Metascape) shows that the top- 2 overrepresented transcriptional networks in the upregulated FEP network are regulated by RELA $(\mathrm{TRR} 0115, \log 10 \mathrm{p}=-38)$ and NFKB1 (TRR00875, $\log 10 \mathrm{p}=-34)$.

Table 1. Results of Molecular Complex Detection (MCODE) analysis performed on upregulated and downregulated differentially expressed proteins in first episode psychosis (FEP) and/or first episode schizophrenia (FES).

\begin{tabular}{|c|c|c|c|}
\hline MCODE Components & GO ID & Biological term & $\log 10(p)$ \\
\hline \multirow{3}{*}{$\begin{array}{l}\text { Upregulated genes in } \\
\text { FEP, MCODE1 } \\
\text { (Biological GO terms) }\end{array}$} & GO:0032496 & response to lipopolysaccharide & -41.6 \\
\hline & GO:0006954 & inflammatory response & -40.8 \\
\hline & GO:0002237 & response to molecule of bacterial origin & -40.8 \\
\hline \multirow{3}{*}{$\begin{array}{l}\text { Upregulated genes in } \\
\text { FEP, MCODE2 (GO, } \\
\text { PANTHER, KEGG, } \\
\text { WikiPaths) }\end{array}$} & $\begin{array}{l}\text { R-HSA- } \\
5357956\end{array}$ & $\begin{array}{l}\text { TNFR1-induced NFkappaB signaling } \\
\text { pathway }\end{array}$ & -10.1 \\
\hline & R-HSA-73887 & death receptor signaling & -9.8 \\
\hline & R-HSA-75893 & TNF signaling & -9.4 \\
\hline \multirow{3}{*}{$\begin{array}{l}\text { Downregulated genes in } \\
\text { FEP, MCODE1 } \\
\text { (Biological GO terms) }\end{array}$} & GO:0048011 & $\begin{array}{l}\text { neurotrophin TRK receptor signaling } \\
\text { pathway }\end{array}$ & -22.5 \\
\hline & GO:0007169 & $\begin{array}{l}\text { transmembrane receptor protein tyrosine } \\
\text { kinase signaling pathway }\end{array}$ & -22.1 \\
\hline & GO:0032989 & cellular component morphogenesis & -21.8 \\
\hline \multirow{3}{*}{$\begin{array}{l}\text { Downregulated genes in } \\
\text { FEP, MCODE2 } \\
\text { (Biological GO terms) }\end{array}$} & GO:0016246 & RNA interference & -15.6 \\
\hline & GO:0035196 & $\begin{array}{l}\text { production of miRNAs involved in gene } \\
\text { silencing by miRNA }\end{array}$ & -15.5 \\
\hline & GO:0070918 & $\begin{array}{l}\text { production of small RNA involved in gene } \\
\text { silencing by RNA }\end{array}$ & -15.3 \\
\hline \multirow{3}{*}{$\begin{array}{l}\text { All seed genes in } \\
\text { FEP/FES, MCODE1 } \\
\text { (Biological GO terms) }\end{array}$} & GO:0001774 & microglial cell activation & -13.2 \\
\hline & GO:0042531 & $\begin{array}{l}\text { positive regulation of tyrosine } \\
\text { phosphorylation of STAT protein }\end{array}$ & -12.3 \\
\hline & GO:0042509 & $\begin{array}{l}\text { regulation of tyrosine phosphorylation of } \\
\text { STAT protein }\end{array}$ & -11.8 \\
\hline
\end{tabular}


Enrichment analysis in FEP/FES.

Figure 4 shows a heatmap with the top-20 biological GO enriched terms in the first FEP/FES cluster indicating that the most important over-represented terms were: inflammatory response, positive regulation of cytokine production, I-kappa kinase/NFkB signaling, and a response to LPS. Figure 5 shows a heatmap with the top-20 biological GO enriched terms in the second cluster of FEP/FES, namely Wnt signaling pathway, cell-cell junction organization, and beta-catenin-TCF complex assembly. Table 2 shows the top GP enriched terms in the complement factors, DISC1 and DROSHA.

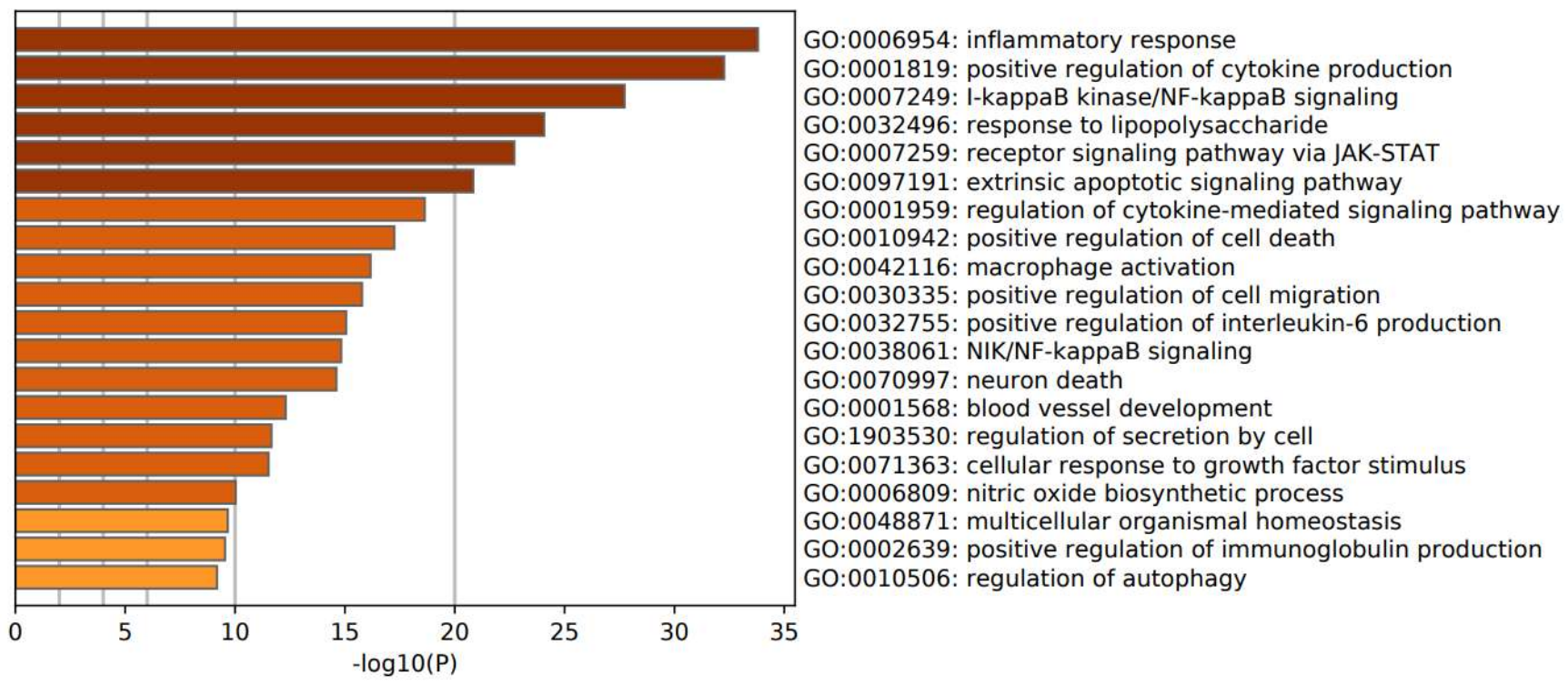

Figure 4. Heatmap of enriched GO terms showing the top-20 biological functions in the first FEP/FES gene cluster (accumulative hypergeometric p-values).

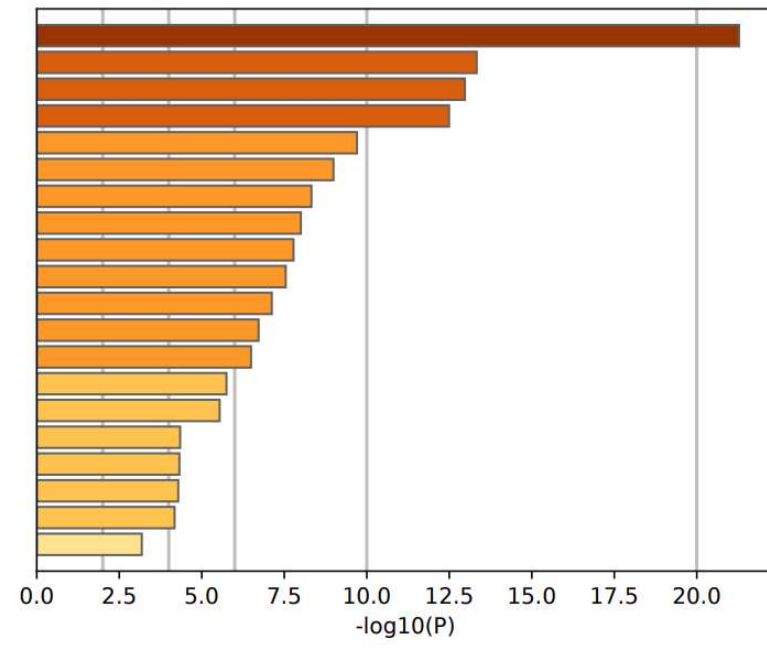

GO:0016055: Wnt signaling pathway GO:0045216: cell-cell junction organization GO:1904837: beta-catenin-TCF complex assembly GO:0001837: epithelial to mesenchymal transition

GO:2001237: negative regulation of extrinsic apoptotic signaling pathway GO:0071407: cellular response to organic cyclic compound GO:0071680: response to indole-3-methanol GO:0043393: regulation of protein binding

GO:1903997: positive regulation of non-membrane spanning protein tyrosine kinase activity GO:0010942: positive regulation of cell death

GO:0007169: transmembrane receptor protein tyrosine kinase signaling pathway GO:0048754: branching morphogenesis of an epithelial tube GO:2000811: negative regulation of anoikis GO:0045596: negative regulation of cell differentiation GO:0042476: odontogenesis

GO:0050673: epithelial cell proliferation

GO:0051090: regulation of DNA-binding transcription factor activity

GO:0007260: tyrosine phosphorylation of STAT protein

GO:0032091: negative regulation of protein binding

GO:0030855: epithelial cell differentiation

Figure 5. Heatmap of enriched GO terms showing the top-20 biological functions in the second FEP/FES gene cluster (accumulative hypergeometric p-values). 
Table 2. Biological GO term classifications of differently expressed proteins in first episode psychosis or schizophrenia.

\begin{tabular}{|c|c|c|c|c|c|}
\hline $\begin{array}{l}\text { Top } \\
\text { genes }\end{array}$ & GO term ID & GO term definition & $\mathbf{P}$ & $\begin{array}{l}\text { P FDR } \\
\text { adjuste } \\
\text { d }\end{array}$ & $\begin{array}{l}\text { Numbe } \\
r \text { of } \\
\text { genes }\end{array}$ \\
\hline \multicolumn{6}{|c|}{ Complement factors } \\
\hline 1 & GO:0098883 & synapse pruning & $\begin{array}{l}1.00 \mathrm{E}- \\
010\end{array}$ & $\begin{array}{l}1.41 \mathrm{E}- \\
006\end{array}$ & 3 \\
\hline 2 & GO:0030449 & regulation of complement activation & $\begin{array}{l}2.02 \mathrm{E}- \\
007\end{array}$ & $\begin{array}{l}1.11 \mathrm{E}- \\
003\end{array}$ & 3 \\
\hline 3 & GO:0002920 & regulation of humoral immune response & $\begin{array}{l}3.18 \mathrm{E}- \\
007\end{array}$ & $\begin{array}{l}1.17 \mathrm{E}- \\
003\end{array}$ & 3 \\
\hline 4 & GO:0006958 & complement activation, classical pathway & $\begin{array}{l}5.40 \mathrm{E}- \\
007\end{array}$ & $\begin{array}{l}1.30 \mathrm{E}- \\
003\end{array}$ & 3 \\
\hline 5 & GO:0002455 & $\begin{array}{l}\text { humoral immune response mediated by } \\
\text { circulating immunoglobulin }\end{array}$ & $\begin{array}{l}5.92 \mathrm{E}- \\
007\end{array}$ & $\begin{array}{l}1.30 \mathrm{E}- \\
003\end{array}$ & 3 \\
\hline 6 & GO:0006956 & complement activation & $\begin{array}{l}7.29 \mathrm{E}- \\
007\end{array}$ & $\begin{array}{l}1.34 \mathrm{E}- \\
003\end{array}$ & 3 \\
\hline 7 & GO:0016064 & $\begin{array}{l}\text { immunoglobulin mediated immune } \\
\text { response }\end{array}$ & $\begin{array}{l}1.08 \mathrm{E}- \\
006\end{array}$ & $\begin{array}{l}1.56 \mathrm{E}- \\
003\end{array}$ & 3 \\
\hline 8 & GO:0019724 & B cell mediated immunity & $\begin{array}{l}1.13 \mathrm{E}- \\
006\end{array}$ & $\begin{array}{l}1.56 \mathrm{E}- \\
003\end{array}$ & 3 \\
\hline 9 & GO:0002449 & lymphocyte mediated immunity & $\begin{array}{l}2.35 \mathrm{E}- \\
006\end{array}$ & $\begin{array}{l}2.66 \mathrm{E}- \\
003\end{array}$ & 3 \\
\hline 10 & GO:0050808 & synapse organization & $\begin{array}{l}2.46 \mathrm{E}- \\
006\end{array}$ & $\begin{array}{l}2.66 \mathrm{E}- \\
003\end{array}$ & 3 \\
\hline \multicolumn{6}{|l|}{ DISC1 } \\
\hline 1 & GO:0021799 & $\begin{array}{l}\text { cerebral cortex radially oriented cell } \\
\text { migration }\end{array}$ & $\begin{array}{l}1.13 \mathrm{E}- \\
008\end{array}$ & $\begin{array}{l}1.25 \mathrm{E}- \\
004\end{array}$ & 3 \\
\hline 2 & GO:0021795 & cerebral cortex cell migration & $\begin{array}{l}3.82 \mathrm{E}- \\
008\end{array}$ & $\begin{array}{l}1.40 \mathrm{E}- \\
004\end{array}$ & 3 \\
\hline 3 & GO:0045773 & positive regulation of axon extension & $\begin{array}{l}3.82 \mathrm{E}- \\
008\end{array}$ & $\begin{array}{l}1.40 \mathrm{E}- \\
004\end{array}$ & 3 \\
\hline 4 & GO:0022029 & telencephalon cell migration & $\begin{array}{l}9.56 \mathrm{E}- \\
008\end{array}$ & $\begin{array}{l}2.46 \mathrm{E}- \\
004\end{array}$ & 3 \\
\hline 5 & GO:0021885 & forebrain cell migration & $\begin{array}{l}1.11 \mathrm{E}- \\
007\end{array}$ & $\begin{array}{l}2.46 \mathrm{E}- \\
004\end{array}$ & 3 \\
\hline 6 & GO:0021954 & $\begin{array}{l}\text { central nervous system neuron } \\
\text { development }\end{array}$ & $\begin{array}{l}2.54 \mathrm{E}- \\
007\end{array}$ & $\begin{array}{l}4.67 \mathrm{E}- \\
004\end{array}$ & 3 \\
\hline 7 & GO:0050772 & positive regulation of axonogenesis & $\begin{array}{l}3.06 \mathrm{E}- \\
007\end{array}$ & $\begin{array}{l}4.81 \mathrm{E}- \\
004\end{array}$ & 3 \\
\hline 8 & GO:0030516 & regulation of axon extension & $\begin{array}{l}4.42 \mathrm{E}- \\
007\end{array}$ & $\begin{array}{l}6.09 \mathrm{E}- \\
004\end{array}$ & 3 \\
\hline 9 & GO:0061387 & regulation of extent of cell growth & $\begin{array}{l}6.67 \mathrm{E}- \\
007\end{array}$ & $\begin{array}{l}8.17 \mathrm{E}- \\
004\end{array}$ & 3 \\
\hline
\end{tabular}




\begin{tabular}{|c|c|c|c|c|c|}
\hline 10 & GO:0021987 & cerebral cortex development & $\begin{array}{l}7.83 E- \\
007\end{array}$ & $\begin{array}{l}8.48 \mathrm{E}- \\
004\end{array}$ & 3 \\
\hline \multicolumn{6}{|c|}{ DROSCHA } \\
\hline 1 & GO:0031053 & primary miRNA processing & $\begin{array}{l}1.84 \mathrm{E}- \\
007\end{array}$ & $\begin{array}{l}2.03 \mathrm{E}- \\
003\end{array}$ & 2 \\
\hline 2 & GO:0010586 & miRNA metabolic process & $\begin{array}{l}1.18 \mathrm{E}- \\
006\end{array}$ & $\begin{array}{l}5.95 \mathrm{E}- \\
003\end{array}$ & 2 \\
\hline 3 & GO:0035196 & $\begin{array}{l}\text { production of miRNAs involved in gene } \\
\text { silencing by miRNA }\end{array}$ & $\begin{array}{l}2.08 \mathrm{E}- \\
006\end{array}$ & $\begin{array}{l}5.95 \mathrm{E}- \\
003\end{array}$ & 2 \\
\hline 4 & GO:0070918 & $\begin{array}{l}\text { production of small RNA involved in gene } \\
\text { silencing by RNA }\end{array}$ & $\begin{array}{l}2.70 \mathrm{E}- \\
006\end{array}$ & $\begin{array}{l}5.95 \mathrm{E}- \\
003\end{array}$ & 2 \\
\hline 5 & GO:0031050 & dsRNA processing & $\begin{array}{l}2.70 \mathrm{E}- \\
006\end{array}$ & $\begin{array}{l}5.95 \mathrm{E}- \\
003\end{array}$ & 2 \\
\hline
\end{tabular}

Electronic Supplementary File (ESF) Figure 1 shows a bar graph with the top-10 performing cellular GO terms which were accumulated in FEP/FES genes indicating that the catenin complex, and cytoplasmatic and vesicle membranes were the most significant cellular terms. ESF Figure 2 shows the top-10 performing REACTOME terms accumulated in the FEP/FES gene list indicating that the first terms pointed towards an immune response and that the top 7, 8, 9, and 10 terms pointed towards different aspects of Toll-Like Receptor (TLR)3/4 signaling. ESF Figure 3 displays the top-10 PANTHER terms, which were over-expressed in the FEP/FES gene list with CCKR signaling map ST, and TLR, apoptosis, Wnt and cadherin signaling pathways as top pathways. ESF Figure 4 displays the top-10 WikiPathway terms which were over-expressed in the FEP/FES gene list with TLR and TLR4 signaling pathway and miRNA involvement being important pathways. Table 1 shows the results of a MCODE analysis performed on all FEP/FES genes and detected a molecular complex (with core genes IFNG, IL6, CCL3, IL4, IL12A, and IL13), which represented microglial cell activation, positive regulation of tyrosine phosphorylation of STAT protein, and regulation of tyrosine phosphorylation of STAT protein. Annotation analysis shows that also a neuroinflammatory response (GO:0150076, pFDR=E-7.13) was accumulated in the seed gene list selection. It is interesting to note that behavior (GO:0007610; $\log 10 \mathrm{p}=-4.941 ; 10$ overlapping genes) and learning and memory (GO:0007611; $\log 10 \mathrm{p}=-4.908$; 7 overlapping genes) accumulated in the FEP/FES genes.

ESF Figure 5 shows a network built with OmicsNet (using InAct; 2581 nodes, 4154 edges, 86 seeds). The top-3 over-represented transcriptional TTRUST networks were: SP1 (132 hits), NFKB1 (95), and RELA (95).

Annotation analysis and annotation visualization.

Figure 6 shows the results of GOnet annotation visualization in FEP/FES depicting the seed protein nodes and the top $10 \mathrm{GO}$ terms (or their most important children). As expected, the GO terms comprised key immune processes including cytokine mediated signaling pathway (GO:0019221, pFDR<1E-10), type-immune response (GO:0042092, pFDR=6.423E-04), positive regulation of $\mathrm{T}$ cell activation $(\mathrm{GO}: 0050870, \mathrm{pFDR}=6.384 \mathrm{E}-04)$, positive regulation of $\mathrm{B}$ cell proliferation (GO:0030890, $\mathrm{pFRD}=2.062 \mathrm{E}-04)$, positive regulation of immunoglobulin production (GO:0002639, pFDR=3.00E-0.6), and positive regulation of myeloid leukocyte differentiation (GO:0002763, pFDR=4.389E-04). Moreover, other important GO terms were: cellular response to LPS (GO:0071222, $\mathrm{pFDR}=1.520 \mathrm{E}-0.8)$, microglial cell activation (GO:0001774, 
$\mathrm{pFDR}=8.875 \mathrm{E}-07)$, positive regulation of gliogenesis $(\mathrm{pFDR}=7.962 \mathrm{E}-04)$, and positive regulation of tyrosine phosphorylation of STAT protein (GO:0042531, pFDR=1.0E-10).

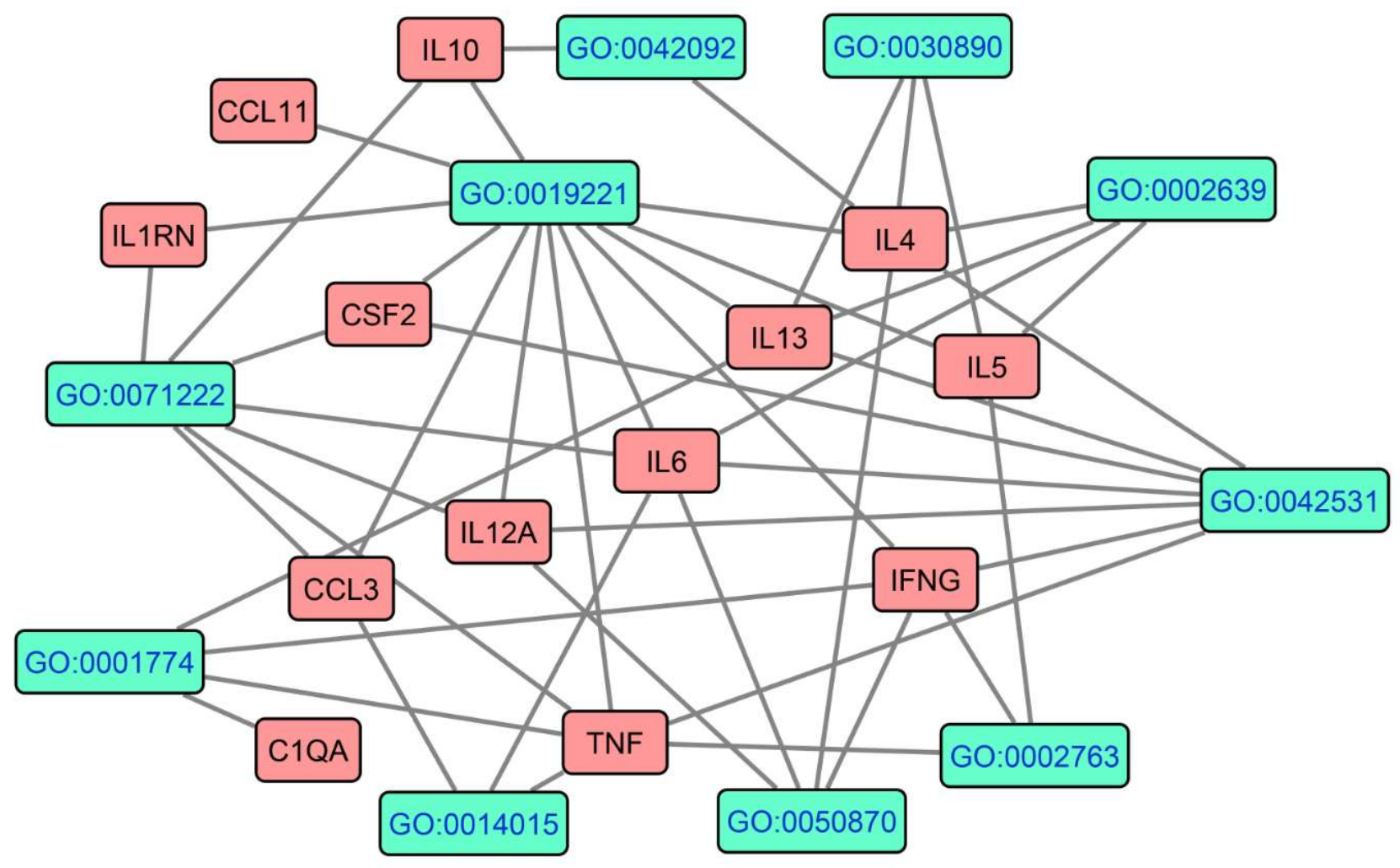

Figure 6. Results of GOnet annotation visualization in FEP/FES depicting the hierarchical structure of GO terms and the upregulated genes. This figure shows the seed protein nodes and the top $10 \mathrm{GO}$ terms (i.e. their most important children).

Figure 7 shows the GOnet annotation analysis results with the GO terms and the four downregulated genes in FEP/FES. The GO term comprised canonical Wnt signaling pathway (GO:0060070, pFDR=3.291E-02), entry of bacterium into host cell (GO:0035635, pFDR=3.155E03), adherens junctions organization (GO:0034332, $\mathrm{p}=3.291 \mathrm{E}-02)$, modulation of chemical synaptic transmission (GO:0050804, $\mathrm{pFDR}=1.990 \mathrm{E}-02)$, synapse assembly (GO:0007416, $\mathrm{pFDR}=3.497 \mathrm{E}-02)$, neuron projection development $(\mathrm{GO}=0031175$, $\mathrm{pFDR}=3.600 \mathrm{E}-02)$, positive regulation of axonogenesis (GO:0050772, $\mathrm{pFDR}=3.291 \mathrm{E}-02)$, positive regulation of neuroblast proliferation (GO:0002052, $\mathrm{pFDR}=9.751 \mathrm{E}-03$ ), cerebral cortex radial glia guided migration (GO:0021801, pFDR=9.751E-03), and cellular response to indole-3-methanol (GO:0071681, $\mathrm{pFDR}=1.69 \mathrm{E}-03)$. 


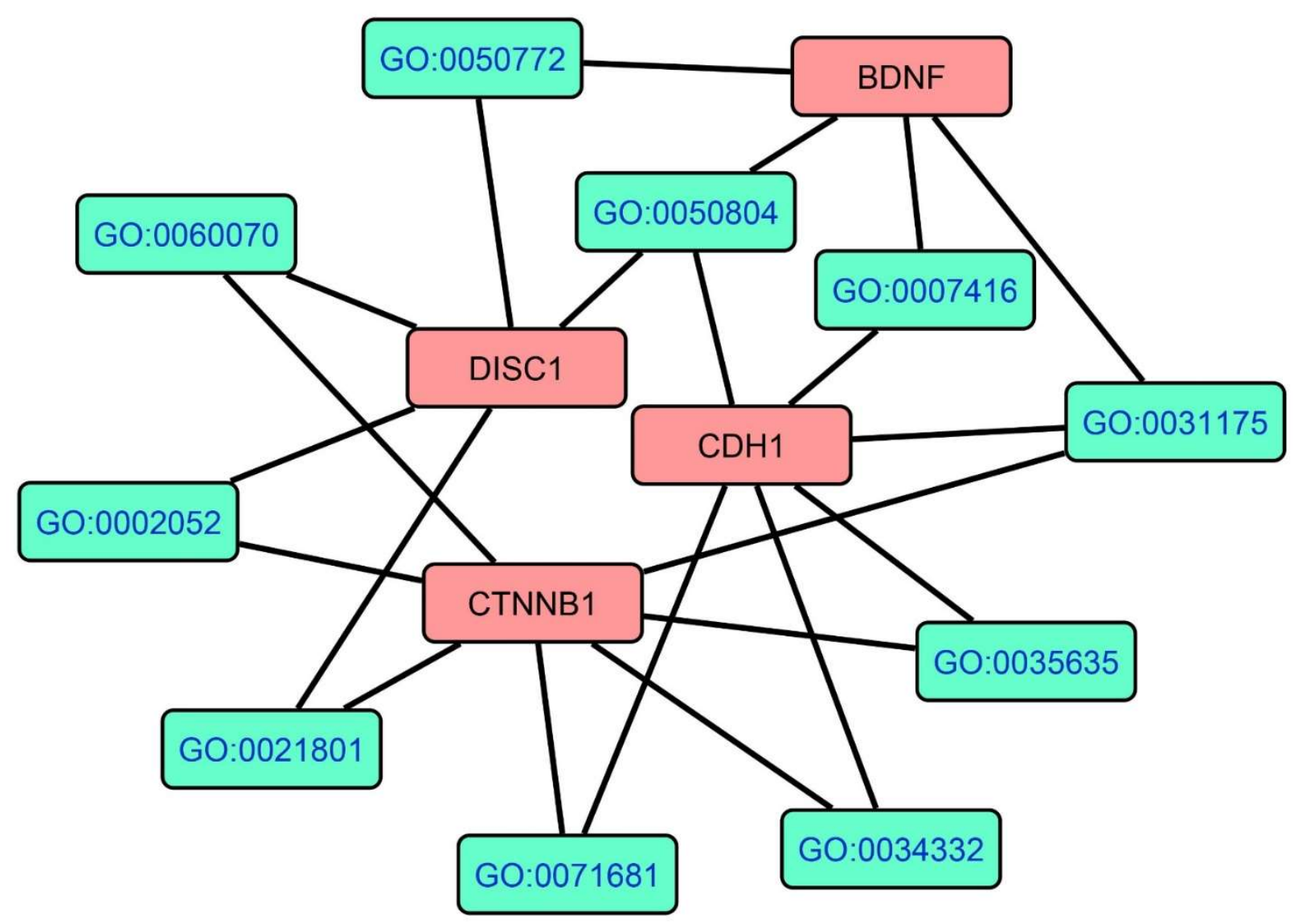

Figure 7. Results of GOnet annotation visualization in FEP/FES depicting the hierarchical structure of GO terms and the downregulated genes. This figure shows the seed protein nodes and the top $10 \mathrm{GO}$ terms (i.e. their most important children).

Figure 8 shows the results of annotation analysis using $\mathrm{R}$ package ClusterProfiler and a custom-made GO list comprising parent and child terms exploring response, cellular or defense response to a variety of stressors, with the aim to differentiate the type of responses including biotic responses. We observed that the most important over-represented GO terms in the FEP/FES gene list were responses to other organism, external biotic stimulus, response to lipid, response to bacterium, response to LPS, whereas there was much less or no evidence for a response to a virus or other biotic (fungal, parasites) or abiotic stimuli. 


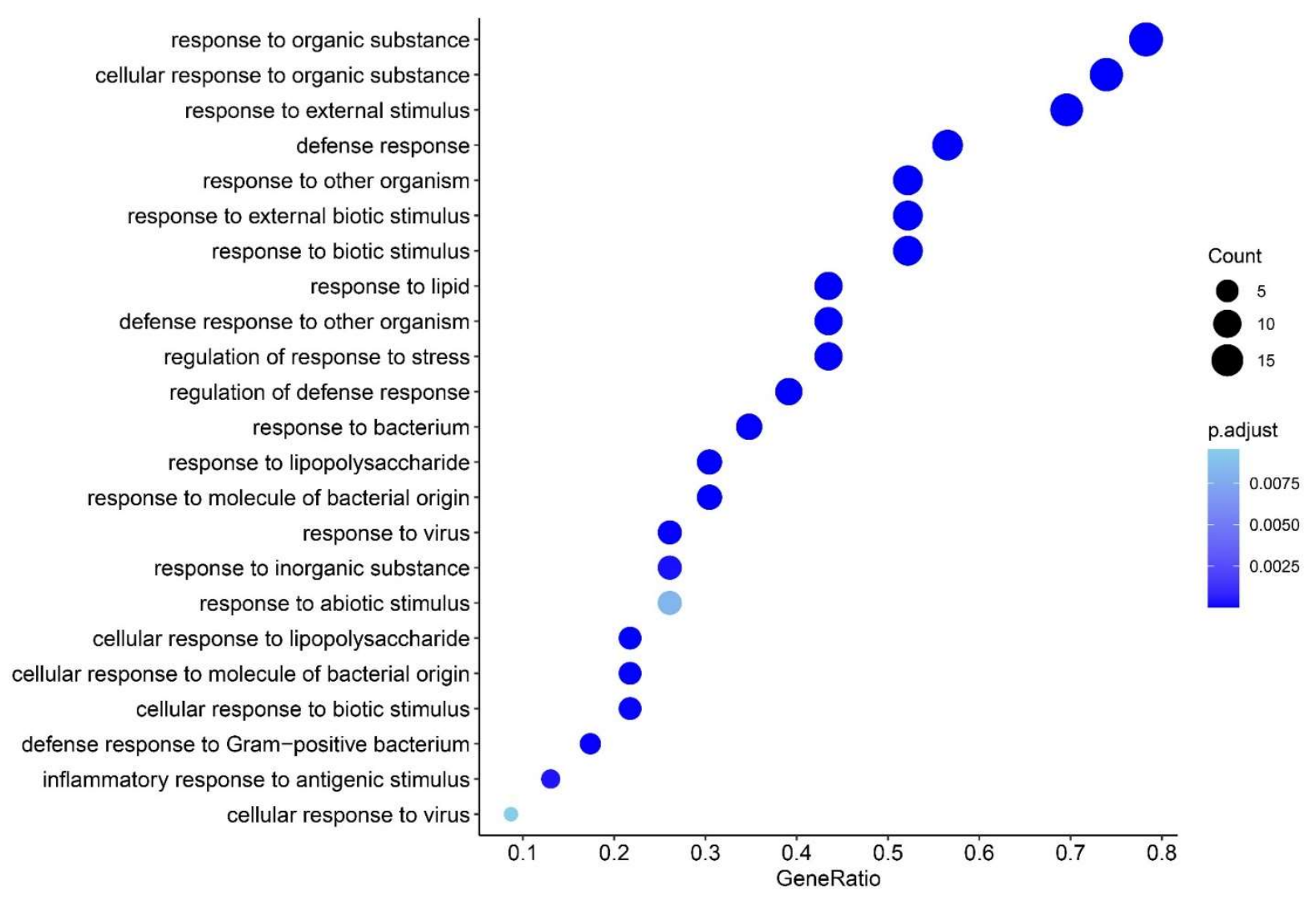

Figure 8 shows the results of annotation analysis using R package "ClusterProfiler" and a custom-made GO list comprising parent and child terms exploring response, cellular or defense response to a variety of stressors, with the aim to differentiate the type of responses including biotic responses. We observed that the most important GO terms which were over-represented in the FEP/FES gene list were responses to other organism, external biotic stimulus, response to lipid, response to bacterium, response to LPS, whereas there was much less evidence for a response to a virus or other biotic or abiotic stimuli.

Consequently, we explored the network of interrelated genes using inBio Discover to delineate which diseases (DOID) are over-represented in the query gene list. Table 3 shows the top-9 DOID disease annotations. This table indicates that the proteins involved in FES/FEP are enriched in a number of immune diseases including immunodeficiency disease and autoimmune disease, and three gastro-intestinal diseases, namely intestinal disease, inflammatory bowel disease, and colitis. ESF Figure 6 shows the extended network and the 4 of the 9 top annotations that were over-represented. The nodes of the extended PPI network involved in immune system and autoimmune disease, and inflammatory bowel and intestinal disease are colored in red, orange, blue, and green, respectively. ESF Figure 7 shows all nodes (in red color) which were accumulated in intestinal disease (DOID:5295). ESF Figure 8 shows the results of an annotation analysis for all differentially expressed proteins using R package ClusterProfiler and the GO list consisting of only leaf children in biological processes. 
Table 3. Results of inBio Discover annotation analysis with the DOID disease annotations classification in first episode psychosis and schizophrenia.

\begin{tabular}{|l|l|l|l|l|l|}
\hline DOID ID & Disease & Size & Overlap & Enrichment & p-value \\
\hline DOID:2914 & Immune system disease & $1.9 \mathrm{k}$ & $89 / 246$ & 3.81 & $2.4 \mathrm{E}-30$ \\
\hline DOID:612 & $\begin{array}{l}\text { Primary Immunodeficiency } \\
\text { syndrome }\end{array}$ & $1.3 \mathrm{k}$ & $70 / 246$ & 4.28 & $2.9 \mathrm{E}-26$ \\
\hline DOID:5295 & Intestinal disease & $1.0 \mathrm{k}$ & $61 / 246$ & 4.89 & $9.2 \mathrm{E}-26$ \\
\hline DOID:0060032 & $\begin{array}{l}\text { Autoimmune disease of the } \\
\text { musculoskeletal system }\end{array}$ & 645 & $48 / 246$ & 6.05 & $4.2 \mathrm{E}-24$ \\
\hline DOID:0050589 & Inflammatory bowel disease & 306 & $35 / 246$ & 9.30 & $8.7 \mathrm{E}-24$ \\
\hline DOID:417 & Autoimmune disease & $1.1 \mathrm{k}$ & $58 / 246$ & 4.42 & $3.0 \mathrm{E}-22$ \\
\hline DOID:9500 & Leukocyte disease & 417 & $38 / 246$ & 7.41 & $3.3 \mathrm{E}-22$ \\
\hline DOID:65 & Connective tissue disease & $1.8 \mathrm{k}$ & $76 / 246$ & 3.35 & $5.3 \mathrm{E}-22$ \\
\hline DOID:0060180 & Colitis & 237 & $30 / 246$ & 10.29 & $8.8 \mathrm{E}-22$ \\
\hline
\end{tabular}

Discussion.

The PPI network of FEP/FES.

The first major finding of this study is that we were able to construct zero and first-order PPI networks of FES/FEP which show high connectivity and some unexpected interactions, including the central role of BDNF. We found that the backbone of the FEP network is shaped by 6 genes (IL6, TNF, IL10, IL4, IFNG, and BDNF) and the backbone of FEP/FES by IL6, TNF, IL10, CCTNB1, CDH1, and BDNF. Moreover, our network analysis revealed two major protein communalities, namely one centered around immune-inflammatory genes and BDNF, and a second cluster around cell-cell junction genes (CTNNB1 and CDH1). Most importantly, BDNF appears to function as a switch between both communalities as it shows interconnections with immune genes and CTNNB1 and the high-affinity receptor of BDNF, namely neurotrophic tyrosine kinase receptor 2 (NTRK2), which was allocated to the cell-cell junction cluster. Another but smaller bridge between both communalities is CDH1 which is interconnected with CTNNB1 and with CSF2, IL4, TNF, IL10, and IL6.

Therefore, it appears that an immune response, as observed in FEP/FES, comprises not only IRS and CIRS components [4], but also different neurotrophic (BDNF, NTF4 and NGFR) and cell adhesion (CTNNB1 and CDH1) factors. By inference, the neurotoxic effects of the immune response may be counterbalanced by CIRS (Th-2 and Treg) [7], neuroprotective, and cellcell adhesion genes. It is tempting to speculate that the participation of neuroprotective and cellcell adhesion genes in this immune network is another conserved regulatory process protecting against detrimental neuro-immune effects.

\section{Trigger factors in FEP and FEP/FES.}

GO annotation and MCODE analysis revealed that the upregulated genes in FEP and the cluster-1 genes in FEP/FES were highly significantly associated with a response to a molecule of 
bacterial origin and a response to LPS. In fact, a response to LPS was the second most important GO term overexpressed in the upregulated proteins in FEP. Moreover, annotation analysis using a custom-made GO list with possible "responses to .." or "cellular responses to .." or a "defense response to .." showed that the most significant paths enriched in the network were responses to an organic substance (determined as cytokine or lipid), an external stimulus, response to other organism or an external biotic stimulus. Further analysis showed that a response to a bacterium and LPS were the most significant paths enriched in the FEP/FES network, whereas a response to a virus was less significant and did not appear in the GO and MCODE enrichment analysis. Moreover, an abiotic stimulus and fungal or parasite stimuli were not significantly enriched.

All in all, it appears that FEP and FEP/FES may be triggered or maintained by a response to LPS of Gram-negative bacteria. These findings corroborate a recent study which reported increased $\operatorname{IgA} / \operatorname{IgM}$ responses to LPS of Gram-negative bacteria in FES and deficit schizophrenia, and that these indicants of bacterial load are strongly associated with the G-CoDe (general cognitive impairments) and symptom profiles, especially psychosis $[7,18]$. Such findings may indicate increased bacterial translocation in FES/FEP through leaky gut (increased gut permeability) with deficits in tight and adherens junctions and the vascular barrier as well [7]. Interestingly, three of the top-9 DOID annotations which were overrepresented in the PPI network of FEP/FES comprised intestinal annotations, including intestinal disease, inflammatory bowel disease, and colitis.

\section{Upregulated pathways, molecular and cellular processes in FEP.}

The third major finding of this study is that the upregulated genes in FEP were enriched in key pathways and cellular functions that play a key role in immune-inflammatory signaling, namely the receptor signaling pathway via Janus kinases / signal transducer and activator of transcription proteins (JAK-STAT) pathway, the TNFR1-induced NFKB signaling pathway, and TNF- and death receptor signaling. Moreover, STAT3 and STAT6 were prominent nodes in the first order network with STAT3 occupying a central position. Many cytokines (e.g. IL2, IL4, IL6, IL10, IL12, IFNG) signal via the JAK-STAT pathway thereby transactivating Janus kinases leading to translocation of STATs to the nucleus and upregulation of cytokine-modifiable genes [19]. The JAK-STAT pathway plays a key role in inflammation, cell death, cell division, polarization of T cells, STAT3 is associated with autoimmune responses, and STAT6 plays a key role in M2 macrophage activation and Th-2 differentiation with production of IL4, IL5, IL9, and IL13 [19,20,21]. Recently, Sharma et al. [22] reported that a subgroups of schizophrenia patients shows increased STAT1 levels.

Our enrichment analyses show that TNF plays an important role in FEP and suggests that TNF-induced I $\kappa B$ kinase (IKK) activation with consequent NF $\kappa B$ translocation to the nucleus is one of the key processes in FEP. Moreover, we found that both NFkB1 and RELA (NFkB p65 unit or transcription factor p65) are the most prominent transcription factors in the FEP network. RELA

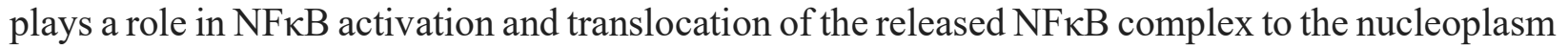

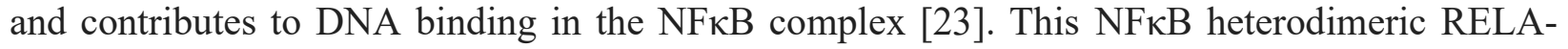
NFKB1 complex functions as a transcriptional activator and plays a key role in gene expression of multiple cytokines [23]. In schizophrenia, it was shown that increased NFKB activity may contribute to cortical immune activation [24]. In a Japanese population, schizophrenia is associated with variants of the RELA gene and has a significant effect on pre-pulse inhibition [25]. Importantly, this pathway is not only induced by TNF, but also by other cytokines and LPS [26]. Previously, we have reviewed the many neurotoxic effects of increased TNF- $\alpha$ levels in 
schizophrenia and especially in deficit schizophrenia [27]. Moreover, the frequency of the TNF2(A) allele, which affects plasma TNF levels, is significantly increased in schizophrenia and TNF2 homozygotes are detected in schizophrenia only [6].

\section{Downregulated pathways, molecular and cellular processes in FEP.}

The fourth major finding is that the downregulated genes were enriched in the receptor protein tyrosine kinase (RTK) and neurotrophin/Trk receptor signaling pathways, cellular component morphogenesis, and production of miRNAs involved in gene silencing. RTK is a family of high-affinity cell surface receptors including Trk which is activated by neurotrophins such as BDNF [28]. Interestingly, RTKs regulate the threshold for macrophage activation thereby promoting homeostasis and protecting tissues from inflammatory damage [29]. BDNF/Trk signaling contributes to axonal growth, axonal guidance, plasticity, dendritic arborization, synapse structure and formation and connections, neurogenesis, differentiation of new neurons and synapses, axonal and dendritic sprouting [30]. Moreover, BDNF may have anti-inflammatory and anti-apoptopic effects via modulation of MyD88/NFKB and PI3K/AKT-signaling pathways [31]. Following bacterial infection, BDNF pretreatment reduces the expression of TNF- $\alpha$, IL-16, IL-1 $\beta$ and the NFאB pathways, and increases IL-10 and Trk expression [31]. LPS-associated inflammation alters BDNF/TrkB signaling in the hippocampus, nucleus accumbens and prefrontal cortex in association with the onset of depressive behaviors [32]. A recent meta-analysis showed that schizophrenia is associated with reduced BDNF with a medium effect size (Hedges $g=-0.458$, $P<0.004)$ and that these effects are not influenced by the drug state of the patients [33]. Moreover, the interaction between $B D N F$ and NTRK2 gene polymorphisms may increase susceptibility to paranoid schizophrenia [34].

We found that the downregulated DISC1 gene is enriched in various GO biological terms indicating neurogenesis, axonogenesis, and axon extension. DISC1 is now established as a risk factor of schizophrenia and other major psychiatric illness and is involved in aspects of adult progenitor proliferation, neurogenesis, neurite outgrowth, cytoskeletal modulation, signal transduction and CTNNB1 abundance [35,36]. It is interesting to note that inflammatory signaling via TLR3 is accompanied by impairments in dendritic spine and growth via effects on MYD88 and, consequently, DISC1 expression [37].

Another highly significant GO path enriched in the downregulated network was the "production of miRNAs involved in gene silencing by miRNA", which may at least in part be ascribed to downregulation of DROSHA, which is a ribonuclease (RNase) III family enzyme and plays a key role in miRNA maturation [38]. In mammals, the miRNA network comprises 5,00010,000 miRNAs which regulate the expression of $60 \%$ of the protein-coding genes through translational silencing and mRNA destabilization [39,40]. Importantly, miRNA regulate the adaptive and innate immune response and act as fine-tuning regulators preventing an overzealous inflammatory response thereby maintaining homeostasis [40]. Many of the miRNAs which are associated with schizophrenia phenotypes [41,42] display immune regulatory effects. For example, miR-9 exerts a negative feedback on NFKB and is dysregulated in neural progenitor cells of schizophrenia patients [43]; miR-132 inhibits inflammation signaling (via acetylcholine, STAT3, and NFKB) and is dysregulated in schizophrenia [44]; miR-146 inhibits inflammatory responses and is downregulated in monocytes of postpartum psychosis patients [45]; and miR-149 inhibits LPS-induced inflammation (via STAT3, NFKB, TNF, IL6) and is a candidate biomarker of psychiatric disease including bipolar disorders [46]. 


\section{Pathways, molecular and cellular processes in FEP/FES.}

The enrichment and annotation analysis revealed other important drug targets in FEP/FES. Firstly, we found that a neuroinflammatory response was enriched in the seed gene FEP/FES list whilst MCODE showed that the molecular complex of IFNG, IL6, IL-12A, CCL3, IL4, and IL13 was strongly associated with microglial cell activation and tyrosine phosphorylation of STAT proteins. These findings extend the findings that schizophrenia is accompanied by microglial activation [47]. Moreover, the upregulated genes in FEP/FES were enriched in "the positive regulation of gliogenesis". In adulthood, gliogenesis is maintained to renew oligodendrocytes, however, following inflammatory disease and injuries, gliogenesis becomes more active (reactive astroytosis or astrogliosis) and may have negative consequences, thereby contributing to immuneinflammatory responses and altering the balance between neurogenesis and gliogenesis [48].

Secondly, WikiPathway and PANTHER enrichment analysis revealed that the upregulated genes were strongly associated with the TLR signaling (especially TLR4) and tolerance pathways. These findings extend those of previous publications indicating activation of the TLR4 proinflammatory pathway in schizophrenia [49].

Thirdly, GO annotation analysis revealed that the cluster 2 genes are enriched in the Wnt/catenin pathway and cell-cell junction organization. Moreover, different combinations of the downregulated genes were associated with the Wnt/catenin pathway (DISC1 and CTNNB1), adherens junctions organization (CDH1 and CTNNB1), synapse assembly (CDH1 and BDNF), neuron projection development (BDNF, CTNNB1 and CDH1), neuroblast proliferation (DISC1 and CTNNB1), cerebral cortex radial glia guided migration (DISC1 and CTNNB1), positive regulation of axonogenesis (BDNF and DISC1), and modulation of chemical synaptic transmission (BDNF, CDH1 and DISC1).

CTNNB1 is a component of the Wnt/ $\beta$-catenin signaling pathway and the E-cadherincatenin adhesion complex, which play a key role in epithelial integrity and tissue architecture maintenance [50,51]. The Wnt/catenin pathway is strongly involved in neurogenesis, axonal spreading and branching, connectivity between pre- and post-synaptic neuronal regions, regulation of synaptic functions and modeling of synaptic structures, modulation of excitatory synaptic transmission, LTP, and post-synaptic protein assembly [52]. The Wnt/ $\beta$-catenin signaling pathway also regulates immune-inflammatory responses and T-cell-inflammation [53-55]. Inflammatory responses due to infections with pathogenic bacteria, may affect the $\mathrm{Wnt} / \beta$-catenin signaling pathway [55] and the E-cadherin-catenin adhesion complex [56]. For example, in inflammatory bowel disease, impairments in the latter complex are affected by the inflammatory milieu and may cause dysregulations of the actin cytoskeleton leading to aberrations in intracellular signaling and transcriptional regulation [57]. Moreover, the Wnt/catenin pathway may regulate BDNF expression, both pathways may have common effector actions [58], and BDNF polymorphisms are associated with changes in the $\mathrm{Wnt} / \beta$-catenin pathway [59]. In hippocampal neurons, BDNF-disruption of cadherin- $\beta$-catenin complexes is associated with increased synapse density [60].

Disorders in the Wnt/catenin pathway were previously described in FES and schizophrenia $[7,61,62]$ and alterations in E-cadherin and beta-catenin levels in FES are strongly associated with increased bacterial translocation [7]. This more generalized disorder in paracellular and cell-cell junctions in FEP/FES may, at least in part, be related with the increased frequency of the Hp2 allele and the Hp2.2 phenotype (prehaptoglobin-2 or zonulin) [63] and increased zonulin levels [64]. Moreover, mutations in the CTNNB1 gene (c.1943A>G) are associated with schizophrenia [65], whilst CTNNB1 KO mice display anxiety behaviors and CTNNB1 KO in paraventricular 
interneurons is accompanied by impairments in social interactions, repetitive behaviors, and object recognition [66]. Association, candidate gene, and genome-wide association studies show that cadherins may be involved in the pathophysiology of schizophrenia $[67,68]$.

Fourthly, exploration of transcriptional regulation showed that SP1, NFкB1 and RELA were the most prominent transcription factors in the FEP/FES network. SP1 or specificity protein 1 (or transcription factor $\mathrm{Sp} 1$ ) is an ubiquitously expressed transcription factor, which regulates the expression of a variety of house-keeping and tissue-restricted genes frequently involved in immune responses, response to DNA damage, and apoptosis [69]. This explains that SP1 is associated with the pathophysiology of some neurodegenerative and neuroinflammatory disorders including Alzheimer's and Huntington's disease, and multiple sclerosis [69]. Interestingly, neurons have a decreased capacity of activating NFkB, but $\kappa B$ cis elements may bind to SP1 [70] and SP1 interacts with RELA to form a complex [71]. In cortical neurons, SP1 is an oxidativelyinduced transcription factor which regulates neuronal survival [72]. In Huntington's disease, pathogenic SP1 cascades cause repression of neuronal genes [73]. Interestingly, both NFkB and SP1 modulate antimicrobial activity against Gram-negative bacteria [74].

Fifthly, biological GO term classifications showed that complement factors were enriched not only in microglial activation and humoral immune responses, but also in synapse pruning and organization. The involvement of complement in FEP/FES agrees with previous findings showing increased plasma $\mathrm{C} 3 \mathrm{C}$ and $\mathrm{C} 4$, and $\mathrm{CSF}$ and brain $\mathrm{C} 4$ complement factors in schizophrenia $[2,75,76]$. Moreover, increased C1qA, C3, and C4 transcripts were reported to be associated with microglial activation in the midbrain of schizophrenia patients [77]. It should be added that FES is accompanied by increased formation of the IgA C1qA CIC, which may have detrimental effects in its own right [7]. Nevertheless, the complement pathways established in FEP/FES are not a key component of the interactome and, therefore, should be considered as secondary phenomena. In addition, also PON1 was not a key component of the interactome and showed only few interactions. Other CIRS components could not be included such as natural IgM responses to oxidatively specific epitopes [7]. Both PON1 and natural IgM are first line innate immune defenses against bacterial infections and display strong anti-inflammatory and antioxidant properties explaining that impairments in both systems contribute to FEP/FES [7].

\section{Conclusions.}

Figure 9 shows a summary of the enrichment and annotation analysis reported in our study. All in all, the analyses suggest that increased bacterial translocation in particular that of Gramnegative bacteria is the most probable trigger and maintaining factor of FEP and FEP/FES causing an immune-inflammatory milieu with involvement of TNF, NFKB/RELA, SP1 and JAK-STAT signaling, including tyrosine phosphorylation of STAT proteins, and death receptor and TLR4 signaling. A specific molecular complex consisting of IFNG, IL6, IL-12A, CCL3, IL4, and IL13 is strongly associated with microglial activation and neuroinflammation, and the upregulated immune network additionally positively regulates gliogenesis. FEP/FES is also accompanied by lowered immune regulation and thus protection against an overzealous inflammatory process due to dysfunctional miRNA maturation, and deficits in neurotrophin/Trk, RTK and Wnt/catenin signaling. 


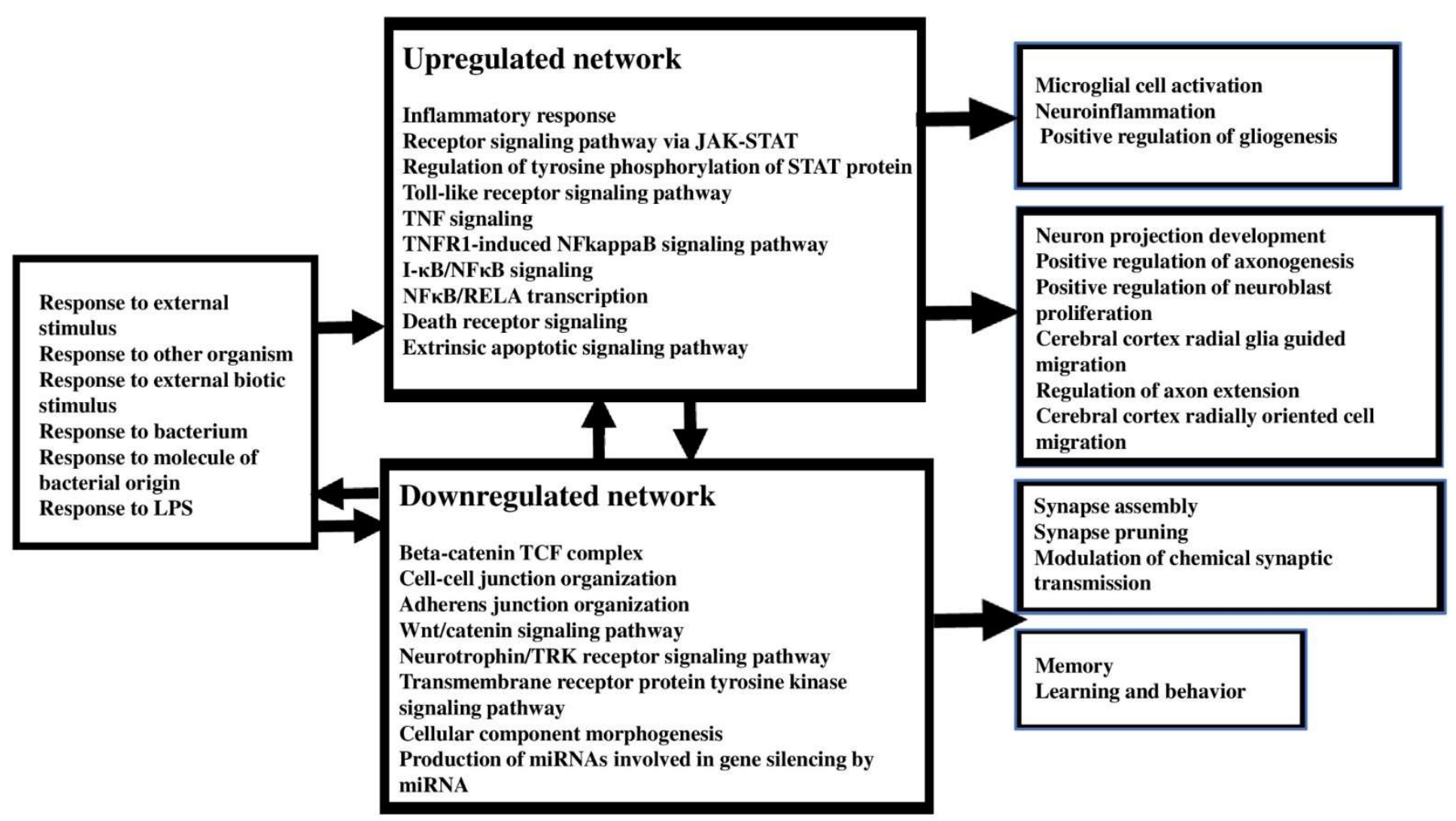

Figure 9. Summary of the findings of the enrichment/annotation analysis using upregulated and downregulated genes in first episode psychosis and schizophrenia.

By inference, individuals with reduced CIRS [4], including miRNA maturation, and deficits in neurotrophin/Trk, RTK and Wnt/catenin signaling, and neuroprotection (including neurotrophin/Trk and Wnt/catenin signaling, lowered DISC1 expression, and interactions between reduced BDNF, CDH1, CTNNB, and DISC1) may be at an increased risk to develop FEP and FES as a consequence of an immune response following bacterial infections and the ensuing neuroimmune toxicity.

Interestingly, almost all pathways or molecular patterns enriched in the interactome of FEP/FES are directly (NFאB/RELA, TLRs, TNF, adherens junctions and cell-cell junctions, complement activation with C1QA CIC formation, neurotrophin/Trk pathway, Wnt signaling, microglial activation, gliogenesis, neurotoxicity) or indirectly (JAK-STAT, DISC1, SP1) affected by LPS. As such, the increased LPS levels in FES may maintain peripheral and central immune activation resulting in neurotoxic effects on central neuronal circuitry, neurogenesis and synapse functions [7]. Disorders in cell-cell junction organization may contribute to the maintenance of increased bacterial translocation and activation of complement cascades with increased IgA C1QA CIC formation, which may further fuel the immune response [7]. The ensuing neuro-immune toxicity may lead to a multitude of neuronal dysfunctions, as shown in Figure 9, and consequently cognitive impairments and schizophrenia behaviors [7]. It should be added that LPS-induced maternal immune activation may have increased the vulnerability to such immune hits by inducing neurodevelopmental disorders with sensitized immune-inflammatory pathways (including in TLR4 and inflammasome) and lowered neuroprotection [78,79]. 
Funding statement

This research has been supported by the Asahi Glass Foundation, Chulalongkorn University Centenary Academic Development Project.

Conflict of interest

The authors have no conflict of interest with any commercial or other association in connection with the submitted article.

Author's contributions.

All the contributing authors have participated in the manuscript. MM designed the study and MM, $\mathrm{KP}$ and AS performed the network, enrichment and annotation analyses. All authors contributed to interpretation of the data and writing of the manuscript.

Compliance with ethical standards.

The study was conducted according to Thai and international ethics and privacy laws.

IRB statement.

This study is a secondary data analysis on existing data using open, deidentified and non-coded data sets and, therefore, this is non-human subjects research, which is not subject to IRB approval.

\section{References}

1. Smith RS, Maes M. The macrophage-T-lymphocyte theory of schizophrenia: additional evidence. Med Hypotheses. 1995;45(2):135-141. doi: 10.1016/0306-9877(95)90062-4. PMID: 8531836.

2. Maes M, Delange J, Ranjan R, Meltzer HY, Desnyder R, Cooremans W, Scharpé S. Acute phase proteins in schizophrenia, mania and major depression: modulation by psychotropic drugs. Psychiatry Res. 1997;66(1):1-11. doi: 10.1016/s0165-1781(96)02915-0. PMID: 9061799.

3. Maes M, Meltzer HY, Bosmans E. Immune-inflammatory markers in schizophrenia: comparison to normal controls and effects of clozapine. Acta Psychiatr Scand. 1994;89(5):346351. doi: 10.1111/j.1600-0447.1994.tb01527.x. PMID: 8067274.

4. Roomruangwong C, Noto C, Kanchanatawan B, Anderson G, Kubera M, Carvalho AF, Maes M. The Role of Aberrations in the Immune-Inflammatory Response System (IRS) and the Compensatory Immune-Regulatory Reflex System (CIRS) in Different Phenotypes of Schizophrenia: the IRS-CIRS Theory of Schizophrenia. Mol Neurobiol. 2020;57(2):778-797. doi: 10.1007/s12035-019-01737-z. Epub 2019 Aug 31. PMID: 31473906.

5. Comer AL, Carrier M, Tremblay MÈ, Cruz-Martín A. The Inflamed Brain in Schizophrenia: The Convergence of Genetic and Environmental Risk Factors That Lead to Uncontrolled Neuroinflammation. Front Cell Neurosci. 2020;14:274. doi: 10.3389/fncel.2020.00274. PMID: 33061891; PMCID: PMC7518314.

6. Boin F, Zanardini R, Pioli R, Altamura CA, Maes M, Gennarelli M. Association between G308A tumor necrosis factor alpha gene polymorphism and schizophrenia. Mol Psychiatry. 2001;6(1):79-82. doi: 10.1038/sj.mp.4000815. PMID: 11244489.

7. Maes M, Vojdani A, Sirivichayakul S, Barbosa DS, Kanchanatawan B. Inflammatory and Oxidative Pathways Are New Drug Targets in Multiple Episode Schizophrenia and Leaky Gut, Klebsiella pneumoniae, and C1q Immune Complexes Are Additional Drug Targets in First 
Episode Schizophrenia. Mol Neurobiol. 2021;58(7):3319-3334. doi: 10.1007/s12035-021-023438. Epub 2021 Mar 6. PMID: 33675500.

8. Noto MN, Maes M, Nunes SOV, Ota VK, Rossaneis AC, Verri WA Jr, Cordeiro Q, Belangero SI, Gadelha A, Bressan RA, Noto C. Activation of the immune-inflammatory response system and the compensatory immune-regulatory system in antipsychotic naive first episode psychosis. Eur Neuropsychopharmacol. 2019;29(3):416-431. doi: 10.1016/j.euroneuro.2018.12.008. Epub 2018 Dec 26. PMID: 30594344.

9. Noto C, Ota VK, Santoro ML, Gouvea ES, Silva PN, Spindola LM, Cordeiro Q, Bressan RA, Gadelha A, Brietzke E, Belangero SI, Maes M. Depression, Cytokine, and Cytokine by Treatment Interactions Modulate Gene Expression in Antipsychotic Naïve First Episode Psychosis. Mol Neurobiol. 2016;53(8):5701-5709. doi: 10.1007/s12035-015-9489-3. Epub 2015 Oct 22. PMID: 26491028.

10. Noto MN, Maes M, Vargas Nunes SO, Ota VK, Cavalcante D, Oliveira G, Rossaneis AC, Verri WA Jr, Cordeiro Q, Belangero SI, Gadelha A, Noto C, Bressan RA. BDNF in antipsychotic naive first episode psychosis: Effects of risperidone and the immune-inflammatory response system. J Psychiatr Res. 2021;141:206-213. doi: 10.1016/j.jpsychires.2021.07.011. Epub ahead of print. PMID: 34246975.

11. Maes M, Sirivichayakul S, Matsumoto AK, Michelin AP, de Oliveira Semeão L, de Lima Pedrão JV, Moreira EG, Barbosa DS, Carvalho AF, Solmi M, Kanchanatawan B. Lowered Antioxidant Defenses and Increased Oxidative Toxicity Are Hallmarks of Deficit Schizophrenia: a Nomothetic Network Psychiatry Approach. Mol Neurobiol. 2020;57(11):4578-4597. doi: 10.1007/s12035-020-02047-5. Epub 2020 Aug 5. PMID: 32754898.

12. Jindal RD, Pillai AK, Mahadik SP, Eklund K, Montrose DM, Keshavan MS. Decreased BDNF in patients with antipsychotic naïve first episode schizophrenia. Schizophr Res. 2010;119(1-3):4751. doi: 10.1016/j.schres.2009.12.035. Epub 2010 Jan 21. PMID: 20096541; PMCID: PMC2868956.

13. Maes M, Kanchanatawan B. In (deficit) schizophrenia, a general cognitive decline partly mediates the effects of neuro-immune and neuro-oxidative toxicity on the symptomatome and quality of life. CNS Spectr. 2021;12:1-10. doi: 10.1017/S1092852921000419. Epub ahead of print. PMID: 33843548.

14. Brinholi FF, Noto C, Maes M, Bonifácio KL, Brietzke E, Ota VK, Gadelha A, Cordeiro Q, Belangero SI, Bressan RA, Vargas HO, Higachi L, de Farias CC, Moreira EG, Barbosa DS. Lowered paraoxonase 1 (PON1) activity is associated with increased cytokine levels in drug naïve first episode psychosis. Schizophr Res. 2015;166(1-3):225-230. doi: 10.1016/j.schres.2015.06.009. Epub 2015 Jun 27. PMID: 26123170.

15. Noto C, Ota VK, Gadelha A, Noto MN, Barbosa DS, Bonifácio KL, Nunes SO, Cordeiro Q, Belangero SI, Bressan RA, Maes M, Brietzke E. Oxidative stress in drug naïve first episode psychosis and antioxidant effects of risperidone. J Psychiatr Res. 2015;68:210-216. doi: 10.1016/j.jpsychires.2015.07.003. Epub 2015 Jul 3. PMID: 26228421.

16. Wu T, Hu E, Xu S, Chen M, Guo P, Dai Z, Feng T, Zhou L, Tang W, Zhan L, Fu x, Liu S, Bo $\mathrm{X}, \mathrm{Yu}$ G. "clusterProfiler 4.0: A universal enrichment tool for interpreting omics data." The Innovation, 2021;2(3):100141. doi: 10.1016/j.xinn.2021.100141.

17. Bader GD, Hogue CW. An automated method for finding molecular complexes in large protein interaction networks. BMC Bioinformatics 2003;4:2. https://doi.org/10.1186/1471-2105-4-2

18. Maes M, Kanchanatawan B, Sirivichayakul S, Carvalho AF. In Schizophrenia, Increased Plasma IgM/IgA Responses to Gut Commensal Bacteria Are Associated with Negative Symptoms, 
Neurocognitive Impairments, and the Deficit Phenotype. Neurotox Res. 2019;35(3):684-698. doi: 10.1007/s12640-018-9987-y. Epub 2018 Dec 15. PMID: 30552634.

19. Morris R, Kershaw NJ, Babon JJ. The molecular details of cytokine signaling via the JAK/STAT pathway. Protein Sci. 2018;27(12):1984-2009. doi: 10.1002/pro.3519. PMID: 30267440; PMCID: PMC6237706.

20. Murray PJ. The JAK-STAT signaling pathway: input and output integration. J Immunol. 2007;178(5):2623-2629. doi: 10.4049/jimmunol.178.5.2623. PMID: 17312100.

21. Gong M, Zhuo X, Ma A. STAT6 Upregulation Promotes M2 Macrophage Polarization to Suppress Atherosclerosis. Med Sci Monit Basic Res. 2017;23:240-249. doi: 10.12659/msmbr.904014. PMID: 28615615; PMCID: PMC5484610.

22. Sharma RP, Rosen C, Melbourne JK, Feiner B, Chase KA. Activated Phosphorylated STAT1 Levels as a Biologically Relevant Immune Signal in Schizophrenia. Neuroimmunomodulation. 2016;23(4):224-229. doi: 10.1159/000450581. Epub 2016 Nov 8. PMID: 27820940; PMCID: PMC5266626.

23. UniProtB. UniProtKB - Q04206 (TF65_HUMAN). RELA - Transcription factor p65 - Homo sapiens (Human) - RELA gene \& protein (uniprot.org). As assessed 23-7-2021.

24. Volk DW, Moroco AE, Roman KM, Edelson JR, Lewis DA. The Role of the Nuclear FactorкB Transcriptional Complex in Cortical Immune Activation in Schizophrenia. Biol Psychiatry. 2019;85(1):25-34. doi: 10.1016/j.biopsych.2018.06.015. Epub 2018 Jun 28. PMID: 30082065; PMCID: PMC6289758.

25. Hashimoto R, Ohi K, Yasuda Y, Fukumoto M, Yamamori H, Takahashi H, Iwase M, Okochi T, Kazui H, Saitoh O, Tatsumi M, Iwata N, Ozaki N, Kamijima K, Kunugi H, Takeda M. Variants of the RELA gene are associated with schizophrenia and their startle responses. Neuropsychopharmacology. 2011;36(9):1921-1931. doi: 10.1038/npp.2011.78. Epub 2011 May 18. PMID: 21593732; PMCID: PMC3154111.

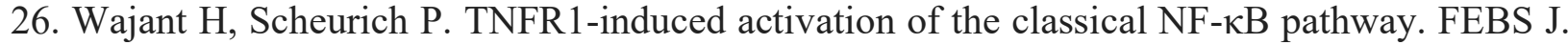
2011;278(6):862-876. doi: 10.1111/j.1742-4658.2011.08015.x. Epub 2011 Feb 8. PMID: 21232017.

27. Maes M, Sirivichayakul S, Matsumoto AK, Maes A, Michelin AP, de Oliveira Semeão L, de Lima Pedrão JV, Moreira EG, Barbosa DS, Geffard M, Carvalho AF, Kanchanatawan B. Increased Levels of Plasma Tumor Necrosis Factor- $\alpha$ Mediate Schizophrenia Symptom Dimensions and Neurocognitive Impairments and Are Inversely Associated with Natural IgM Directed to Malondialdehyde and Paraoxonase 1 Activity. Mol Neurobiol. 2020;57(5):2333-2345. doi: 10.1007/s12035-020-01882-w. Epub 2020 Feb 10. PMID: 32040834.

28. Leopold AV, Chernov KG, Shemetov AA, Verkhusha VV. Neurotrophin receptor tyrosine kinases regulated with near-infrared light. Nat Commun. 2019;10(1):1129. doi: 10.1038/s41467019-08988-3. PMID: 30850602; PMCID: PMC6408446.

29. Correll PH, Morrison AC, Lutz MA. Receptor tyrosine kinases and the regulation of macrophage activation. J Leukoc Biol. 2004;75(5):731-737. doi: 10.1189/jlb.0703347. Epub 2004 Jan 14. PMID: 14726496.

30. Creative Diagnostics. Neurotrophin signaling pathway. Neurotrophin Signaling Pathway Creative Diagnostics (creative-diagnostics.com). As assessed 18-7-2021.

31. Xu D, Lian D, Wu J, Liu Y, Zhu M, Sun J, He D, Li L. Brain-derived neurotrophic factor reduces inflammation and hippocampal apoptosis in experimental Streptococcus pneumoniae meningitis. J Neuroinflammation. 2017;14(1):156. doi: 10.1186/s12974-017-0930-6. PMID: 28778220 ; PMCID: PMC5545027. 
32. Zhang JC, Yao W, Hashimoto K. Brain-derived Neurotrophic Factor (BDNF)-TrkB Signaling in Inflammation-related Depression and Potential Therapeutic Targets. Curr Neuropharmacol. 2016;14(7):721-731. doi: 10.2174/1570159x14666160119094646. PMID: 26786147; PMCID: PMC5050398.

33. Green MJ, Matheson SL, Shepherd A, Weickert CS, Carr VJ. Brain-derived neurotrophic factor levels in schizophrenia: a systematic review with meta-analysis. Mol Psychiatry. 2011;16(9):960-972. doi: 10.1038/mp.2010.88. Epub 2010 Aug 24. PMID: 20733577.

34. Lin Z, Su Y, Zhang C, Xing M, Ding W, Liao L, Guan Y, Li Z, Cui D. The interaction of BDNF and NTRK2 gene increases the susceptibility of paranoid schizophrenia. PLoS One. 2013;8(9):e74264. doi: 10.1371/journal.pone.0074264. PMID: 24069289; PMCID: PMC3775790.

35. Hennah W, Thomson P, Peltonen L, Porteous D. Genes and schizophrenia: beyond schizophrenia: the role of DISC1 in major mental illness. Schizophr Bull. 2006;32(3):409-416. doi: 10.1093/schbul/sbj079. Epub 2006 May 12. PMID: 16699061; PMCID: PMC2632250.

36. UniProt. UniProtKB - Q9NRI5 (DISC1_HUMAN). DISC1 - Disrupted in schizophrenia 1 protein - Homo sapiens (Human) - DISC1 gene \& protein (uniprot.org). As assessed 18-7-2021.

37. Chen CY, Liu HY, Hsueh YP. TLR3 downregulates expression of schizophrenia gene Disc1 via MYD88 to control neuronal morphology. EMBO Rep. 2017;18(1):169-183. doi: 10.15252/embr.201642586. Epub 2016 Dec 15. PMID: 27979975; PMCID: PMC5210159.

38. Aharoni R, Tobi D. Dynamical comparison between Drosha and Dicer reveals functional motion similarities and dissimilarities. PLoS One. 2019;14(12):e0226147. doi: 10.1371/journal.pone.0226147. PMID: 31821368; PMCID: PMC6903759.

39. Catalanotto C, Cogoni C, Zardo G. MicroRNA in Control of Gene Expression: An Overview of Nuclear Functions. Int J Mol Sci. 2016;17(10):1712. doi: 10.3390/ijms17101712. PMID: 27754357 ; PMCID: PMC5085744.

40. Tahamtan A, Teymoori-Rad M, Nakstad B, Salimi V. Anti-Inflammatory MicroRNAs and Their Potential for Inflammatory Diseases Treatment. Front Immunol. 2018;9:1377. doi: 10.3389/fimmu.2018.01377. PMID: 29988529; PMCID: PMC6026627.

41. Caputo V, Ciolfi A, Macri S, Pizzuti A. The emerging role of MicroRNA in schizophrenia. CNS Neurol Disord Drug Targets. 2015;14(2):208-221. doi: 10.2174/1871527314666150116124253. PMID: 25613509.

42. Cao T, Zhen XC. Dysregulation of miRNA and its potential therapeutic application in schizophrenia. CNS Neurosci Ther. 2018;24(7):586-597. doi: 10.1111/cns.12840. Epub 2018 Mar 12. PMID: 29529357; PMCID: PMC6490029.

43. Topol A, Zhu S, Hartley BJ, English J, Hauberg ME, Tran N, Rittenhouse CA, Simone A, Ruderfer DM, Johnson J, Readhead B, Hadas Y, Gochman PA, Wang YC, Shah H, Cagney G, Rapoport J, Gage FH, Dudley JT, Sklar P, Mattheisen M, Cotter D, Fang G, Brennand KJ. Dysregulation of miRNA-9 in a Subset of Schizophrenia Patient-Derived Neural Progenitor Cells. Cell Rep. 2016;15(5):1024-1036. doi: 10.1016/j.celrep.2016.03.090. Epub 2016 Apr 21. Erratum in: Cell Rep. 2017 Sep 5;20(10):2525. PMID: 27117414; PMCID: PMC4856588.

44. Miller BH, Zeier Z, Xi L, Lanz TA, Deng S, Strathmann J, Willoughby D, Kenny PJ, Elsworth JD, Lawrence MS, Roth RH, Edbauer D, Kleiman RJ, Wahlestedt C. MicroRNA-132 dysregulation in schizophrenia has implications for both neurodevelopment and adult brain function. Proc Natl Acad Sci U S A. 2012;109(8):3125-3130. doi: 10.1073/pnas.1113793109. Epub 2012 Feb 6. PMID: 22315408; PMCID: PMC3286960. 
45. Weigelt K, Bergink V, Burgerhout KM, Pescatori M, Wijkhuijs A, Drexhage HA. Downregulation of inflammation-protective microRNAs $146 \mathrm{a}$ and 212 in monocytes of patients with postpartum psychosis. Brain Behav Immun. 2013;29:147-155. doi: 10.1016/j.bbi.2012.12.018. Epub 2013 Jan 4. PMID: 23295264.

46. Choi JL, Kao PF, Itriago E, Zhan Y, Kozubek JA, Hoss AG, Banigan MG, Vanderburg CR, Rezvani AH, Latourelle JC, Cabral H, Delalle I. miR-149 and miR-29c as candidates for bipolar disorder biomarkers. Am J Med Genet B Neuropsychiatr Genet. 2017;174(3):315-323. doi: 10.1002/ajmg.b.32518. Epub 2017 Feb 12. PMID: 28190298.

47. van Rees GF. The involvement of microglial activation in schizophrenia. University of Cambridge, Queens College, November 2017. vanRees-2018-PhD.pdf (cam.ac.uk). As assessed 18-7-2021.

48. Rusznák Z, Henskens W, Schofield E, Kim WS, Fu Y. Adult Neurogenesis and Gliogenesis: Possible Mechanisms for Neurorestoration. Exp Neurobiol. 2016;25(3):103-112. doi: 10.5607/en.2016.25.3.103. Epub 2016 Jun 16. PMID: 27358578; PMCID: PMC4923354.

49. García-Bueno B, Gassó P, MacDowell KS, Callado LF, Mas S, Bernardo M, Lafuente A, Meana JJ, Leza JC. Evidence of activation of the Toll-like receptor-4 proinflammatory pathway in patients with schizophrenia. J Psychiatry Neurosci. 2016;41(3):E46-55. doi: 10.1503/jpn.150195. PMID: 27070349; PMCID: PMC4853215.

50. Tian X, Liu Z, Niu B, Zhang J, Tan TK, Lee SR, Zhao Y, Harris DC, Zheng G. E-cadherin/ $\beta$ catenin complex and the epithelial barrier. J Biomed Biotechnol. 2011;2011:567305. doi: 10.1155/2011/567305. Epub 2011 Oct 11. PMID: 22007144; PMCID: PMC3191826.

51. van Roy F, Berx G. The cell-cell adhesion molecule E-cadherin. Cell Mol Life Sci. 2008;65(23):3756-3788. doi: 10.1007/s00018-008-8281-1. PMID: 18726070.

52. Oliva CA, Vargas JY, Inestrosa NC. Wnts in adult brain: from synaptic plasticity to cognitive deficiencies. Front Cell Neurosci. 2013;7:224. doi: 10.3389/fncel.2013.00224. PMID: 24348327; PMCID: PMC3847898.

53. Jridi I, Canté-Barrett K, Pike-Overzet K, Staal FJT. Inflammation and Wnt Signaling: Target for Immunomodulatory Therapy? Front Cell Dev Biol. 2021;8:615131. doi: 10.3389/fcell.2020.615131. PMID: 33614624; PMCID: PMC7890028.

54. Li X, Xiang Y, Li F, Yin C, Li B, Ke X. WNT/ß-Catenin Signaling Pathway Regulating T Cell-Inflammation in the Tumor Microenvironment. Front Immunol. 2019;10:2293. doi: 10.3389/fimmu.2019.02293. PMID: 31616443; PMCID: PMC6775198.

55. Silva-García O, Valdez-Alarcón JJ, Baizabal-Aguirre VM. The Wnt/ $\beta$-catenin signaling pathway controls the inflammatory response in infections caused by pathogenic bacteria. Mediators Inflamm. 2014;2014:310183. doi: 10.1155/2014/310183. Epub 2014 Jul 17. PMID: 25136145 ; PMCID: PMC4127235.

56. Devaux CA, Mezouar S, Mege JL. The E-Cadherin Cleavage Associated to Pathogenic Bacteria Infections Can Favor Bacterial Invasion and Transmigration, Dysregulation of the Immune Response and Cancer Induction in Humans. Front Microbiol. 2019;10:2598. doi: 10.3389/fmicb.2019.02598. PMID: 31781079; PMCID: PMC6857109.

57. Mehta S, Nijhuis A, Kumagai T, Lindsay J, Silver A. Defects in the adherens junction complex (E-cadherin/ $\beta$-catenin) in inflammatory bowel disease. Cell Tissue Res. 2015;360(3):749-60. doi: 10.1007/s00441-014-1994-6. Epub 2014 Sep 20. PMID: 25238996.

58. Yi H, Hu J, Qian J, Hackam AS. Expression of brain-derived neurotrophic factor is regulated by the Wnt signaling pathway. Neuroreport. 2012;23(3):189-194. doi: 10.1097/WNR.0b013e32834fab06. PMID: 22198686; PMCID: PMC3265333. 
59. Mallei A, Ieraci A, Corna S, Tardito D, Lee FS, Popoli M. Global epigenetic analysis of BDNF Val66Met mice hippocampus reveals changes in dendrite and spine remodeling genes. Hippocampus. 2018;28(11):783-795. doi: 10.1002/hipo.22991. PMID: 30067287.

60. Bamji SX, Rico B, Kimes N, Reichardt LF. BDNF mobilizes synaptic vesicles and enhances synapse formation by disrupting cadherin-beta-catenin interactions. J Cell Biol. 2006;174(2):289299. doi: 10.1083/jcb.200601087. Epub 2006 Jul 10. PMID: 16831887; PMCID: PMC2064188.

61. Hoseth EZ, Krull F, Dieset I, Mørch RH, Hope S, Gardsjord ES, Steen NE, Melle I, Brattbakk HR, Steen VM, Aukrust P, Djurovic S, Andreassen OA, Ueland T. Exploring the Wnt signaling pathway in schizophrenia and bipolar disorder. Transl Psychiatry. 2018;8(1):55. doi: 10.1038/s41398-018-0102-1. PMID: 29507296; PMCID: PMC5838215.

62. Al-Dujaili AH, Mousa RF, Al-Hakeim HK, Maes M. High Mobility Group Protein 1 and Dickkopf-Related Protein 1 in Schizophrenia and Treatment-Resistant Schizophrenia: Associations with Interleukin-6, Symptom Domains, and Neurocognitive Impairments. Schizophr Bull. 2021;47(2):530-541. doi: 10.1093/schbul/sbaa136. PMID: 32971537; PMCID: PMC7965081.

63. Maes M, Delanghe J, Bocchio Chiavetto L, Bignotti S, Tura GB, Pioli R, Zanardini R, Altamura CA. Haptoglobin polymorphism and schizophrenia: genetic variation on chromosome 16. Psychiatry Res. 2001;104(1):1-9. doi: 10.1016/s0165-1781(01)00298-0. PMID: 11600184.

64. Maes M, Vojdani A, Galecki P, Kanchanatawan B. How to Construct a Bottom-Up Nomothetic Network Model and Disclose Novel Nosological Classes by Integrating Risk Resilience and Adverse Outcome Pathways with the Phenome of Schizophrenia. Brain Sci. 2020;10(9):645. doi: 10.3390/brainsci10090645. PMID: 32957709; PMCID: PMC7565440.

65. Levchenko A, Davtian S, Freylichman O, Zagrivnaya M, Kostareva A, Malashichev Y. Betacatenin in schizophrenia: Possibly deleterious novel mutation. Psychiatry Res. 2015;228(3):843848. doi: 10.1016/j.psychres.2015.05.014. Epub 2015 May 19. PMID: 26027441.

66. Dong F, Jiang J, McSweeney C, Zou D, Liu L, Mao Y. Deletion of CTNNB1 in inhibitory circuitry contributes to autism-associated behavioral defects. Hum Mol Genet. 2016;25(13):27382751. doi: 10.1093/hmg/ddw131. Epub 2016 Apr 30. PMID: 27131348; PMCID: PMC5181638.

67. Redies C, Hertel N, Hübner CA. Cadherins and neuropsychiatric disorders. Brain Res. 2012;1470:130-144. doi: 10.1016/j.brainres.2012.06.020. Epub 2012 Jul 2. PMID: 22765916.

68. Hawi Z, Tong J, Dark C, Yates H, Johnson B, Bellgrove MA. The role of cadherin genes in five major psychiatric disorders: A literature update. Am J Med Genet B Neuropsychiatr Genet. 2018;177(2):168-180. doi: 10.1002/ajmg.b.32592. Epub 2017 Sep 18. PMID: 28921840.

69. O'Connor L, Gilmour J, Bonifer C. The Role of the Ubiquitously Expressed Transcription Factor Sp1 in Tissue-specific Transcriptional Regulation and in Disease. Yale J Biol Med. 2016;89(4):513-525. PMID: 28018142; PMCID: PMC5168829.

70. Mao XR, Moerman-Herzog AM, Chen Y, Barger SW. Unique aspects of transcriptional regulation in neurons--nuances in NFkappaB and Sp1-related factors. J Neuroinflammation. 2009;6:16. doi: 10.1186/1742-2094-6-16. PMID: 19450264; PMCID: PMC2693111.

71. Sif S, Gilmore TD. Interaction of the v-Rel oncoprotein with cellular transcription factor Sp1. J Virol. 1994;68(11):7131-8. doi: 10.1128/JVI.68.11.7131-7138.1994. PMID: 7933095; PMCID: PMC237152.

72. Ryu H, Lee J, Zaman K, Kubilis J, Ferrante RJ, Ross BD, Neve R, Ratan RR. Sp1 and Sp3 are oxidative stress-inducible, antideath transcription factors in cortical neurons. J Neurosci. 2003;23(9):3597-606. doi: 10.1523/JNEUROSCI.23-09-03597.2003. PMID: 12736330; PMCID: PMC6742168. 
73. Ravache M, Weber C, Mérienne K, Trottier Y. Transcriptional activation of REST by Sp1 in Huntington's disease models. PLoS One. 2010;5(12):e14311. doi: 10.1371/journal.pone.0014311. PMID: 21179468; PMCID: PMC3001865.

74. Zhao JG, Zhou L, Jin JY, Zhao Z, Lan J, Zhang YB, Zhang QY, Gui JF. Antimicrobial activityspecific to Gram-negative bacteria and immune modulation-mediated NF-kappaB and Sp1 of a medaka beta-defensin. Dev Comp Immunol. 2009;33(4):624-37. doi: 10.1016/j.dci.2008.11.006. Epub 2008 Dec 11. PMID: 19084554.

75. Gallego JA, Blanco EA, Morell C, Lencz T, Malhotra AK. Complement component C4 levels in the cerebrospinal fluid and plasma of patients with schizophrenia. Neuropsychopharmacology. 2021;46(6):1140-1144. doi: 10.1038/s41386-020-00867-6. Epub 2020 Sep 22. PMID: 32961544; PMCID: PMC8115103.

76. Rey R, Suaud-Chagny MF, Bohec AL, Dorey JM, d'Amato T, Tamouza R, Leboyer M. Overexpression of complement component $\mathrm{C} 4$ in the dorsolateral prefrontal cortex, parietal cortex, superior temporal gyrus and associative striatum of patients with schizophrenia. Brain Behav Immun. 2020;90:216-225. doi: 10.1016/j.bbi.2020.08.019. Epub 2020 Aug 19. PMID: 32827700. 77. Purves-Tyson TD, Robinson K, Brown AM, Boerrigter D, Cai HQ, Weissleder C, Owens SJ, Rothmond DA, Shannon Weickert C. Increased Macrophages and C1qA, C3, C4 Transcripts in the Midbrain of People with Schizophrenia. Front Immunol. 2020;11:2002. doi: 10.3389/fimmu.2020.02002. PMID: 33133060; PMCID: PMC7550636.

78. Talukdar PM, Abdul F, Maes M, Berk M, Venkatasubramanian G, Kutty BM, Debnath M. A proof-of-concept study of maternal immune activation mediated induction of Toll-like receptor (TLR) and inflammasome pathways leading to neuroprogressive changes and schizophrenia-like behaviours in offspring. Eur Neuropsychopharmacol. 2021;52:48-61. doi: 10.1016/j.euroneuro.2021.06.009. Epub ahead of print. PMID: 34261013.

79. Talukdar PM, Abdul F, Maes M, Binu VS, Venkatasubramanian G, Kutty BM, Debnath M. Maternal Immune Activation Causes Schizophrenia-like Behaviors in the Offspring through Activation of Immune-Inflammatory, Oxidative and Apoptotic Pathways, and Lowered Antioxidant Defenses and Neuroprotection. Mol Neurobiol. 2020;57(10):4345-4361. doi: 10.1007/s12035-020-02028-8. Epub 2020 Jul 27. PMID: 32720073. 